Canadian University Music Review

Canadian University Music Review

Revue de musique des universités canadiennes

\title{
The First Movement of Beethoven's Opus 109: Compositional Genesis and Structural Dialectic
}

\section{Kevin Bazzana}

Volume 12, numéro 1, 1992

URI : https://id.erudit.org/iderudit/1014209ar

DOI : https://doi.org/10.7202/1014209ar

Aller au sommaire du numéro

Éditeur(s)

Canadian University Music Society / Société de musique des universités canadiennes

ISSN

0710-0353 (imprimé)

2291-2436 (numérique)

Découvrir la revue

Citer cet article

Bazzana, K. (1992). The First Movement of Beethoven's Opus 109:

Compositional Genesis and Structural Dialectic. Canadian University Music

Review / Revue de musique des universités canadiennes, 12(1), 1-36.

https://doi.org/10.7202/1014209ar

All Rights Reserved (C Canadian University Music Society / Société de musique des universités canadiennes, 1991
Ce document est protégé par la loi sur le droit d'auteur. L'utilisation des services d'Érudit (y compris la reproduction) est assujettie à sa politique d'utilisation que vous pouvez consulter en ligne.

https://apropos.erudit.org/fr/usagers/politique-dutilisation/ 


\title{
THE FIRST MOVEMENT OF BEETHOVEN'S OPUS 109: COMPOSITIONAL GENESIS AND STRUCTURAL DIALECTIC*
}

\author{
Kevin Bazzana
}

Beethoven's Piano Sonata in E Major, Opus 109, has recently received intense scholarly attention. William Meredith and Nicholas Marston, both authors of Ph.D. dissertations on the sources for Opus 109 (Meredith 1985a; Marston 1986a), have published diverging accounts of its elusive genesis (Meredith 1985b; Marston 1986b), and Marston's dissertation is to be published by Oxford University Press. William Kinderman discusses the genesis and structure of the first movement in a recent article (1988), ${ }^{1}$ and has produced, for forthcoming publication by the Beethoven-Haus in Bonn, an edition of the desk sketchbook Artaria 195, which contains important work on the second and third movements. And Marston, in another article (1986c), ${ }^{2}$ and Kevin Korsyn, in a Ph.D. dissertation on late Beethoven (1983: 31-45, 209-214), analyze at length the Vivace $^{3}$ sections of the first movement, both developing a structural relationship

* This article is a revised and expanded version of a paper entitled "The Genesis of the First Movement of Beethoven's Sonata in E, Op. 109", read at the Northwest Beethoven Festival and International Symposium on Beethoven's Orchestral Music at the University of Victoria, March 20, 1986.

${ }^{1}$ I am very grateful to Dr. Kinderman for allowing me to read this article before publication, for providing me with copies of source materials for Opus 109, and for many other acts of personal and scholarly generosity without which this article could not have been researched and written.

2 The introduction to Marston's Appendix (1986c: 36-37) gives an excellent overview of all of the sketches for Opus 109. I have chosen not to repeat this information in my own Appendix, save that which is directly relevant to the one source (Grasnick $20 \mathrm{~b}$ ) from which my sketch examples are drawn.

${ }^{3}$ The opening tempo designation in both the autograph (Reinschrift) and the corrected copy (überprüfte Abschrift) for Opus 109 is Vivace; however, the first edition (Berlin: Adolph Martin Schlesinger, October 1821) has Vivace ma non troppo. Meredith (1985a: I, 217-218) notes that this major change "is not reflected in Beethoven's errata list for the edition. It is hard to accept that Beethoven would have allowed the addition 'ma non troppo' by another hand, would not have noticed the alteration, and would not have mentioned the correction to Schlesinger." I believe with Meredith that Vivace ma non troppo represents Beethoven's final intention, and that this tempo is also more satisfying musically. In this article, however, merely for typographical convenience, I am using Vivace. 
between the first and third movements, with Marston drawing substantially on Beethoven's surviving sketches.

Less well documented in the critical literature are the two fantastical adagio espressivo passages that are juxtaposed in such striking fashion with the Vivace material in the first movement. These passages brusquely interrupt the smooth texture and diatonic placidity of the opening measures of the exposition and recapitulation, and delay firm cadences (in the dominant and tonic, respectively) through several seemingly improvisatory measures. The adagio sections stand in the place of an expected second subject group, yet do not behave in normal Classical fashion: they take up at least half of the performance time of the movement, ${ }^{4}$ and in the case of the exposition, the dominant modulation is definitively reached only with the completion of the second group, rather than before it, as in a typical sonata-allegro movement. However unprecedented, these adagio sections do contribute greatly to the expressive power of the movement, which is inconceivable without them. But they resist the kind of systematic analysis that reveals, within the Vivace material, a structure explicitly built on the large-scale projection of a germinal motive. The adagio sections are slipperier, and yield their secrets only to a more flexible analytical methodology.

Sketch studies provide a valuable aid to analysis of much of the first movement, but understanding of the most powerful and climactic passages in both adagios is hampered by holes in the sketch evidence. While early sketches for the adagios survive, no extant sketches document the surprising appearance of D\# Major in $\mathrm{m}$. 13, or the climactic shift to C Major in mm. 61-62 - two decisive events in the first movement. ${ }^{5}$ The final autograph, or Reinschrift, ${ }^{6}$ for Opus 109 is remarkably clear, for reasons Beethoven himself noted, ${ }^{7}$ and the two adagios, whose last appearances in the sketches differ in many ways from the final score, are entered with no apparent hesitation or signs of composition. If Beethoven did

\footnotetext{
4 The timings in Maurizio Pollini's 1976 recording (Deutsche Grammophon stereo 2530 645) are typical: the three Vivace sections total 1'34", the two adagios 1'39".

5 Similar gaps exist in the sketches for the other two movements. None of the extant sketches for the second movement contain work closely presaging the extraordinary passage at $\mathrm{mm}$. 83-105, which culminates in the climactic direct juxtaposition of a V/V chord (F\# Major) with the $E$ Minor tonic recapitulation. And ninety percent of the surviving sketches for the third movement are for variation ideas never included in the final set, with only four substantial sketches surviving for those variations eventually chosen. See Meredith 1985a: I, 373.

${ }^{6}$ The Reinschrift for Opus 109 is housed in the Library of Congress, Washington. It was published in facsimile in 1965 by the Robert Owen Lehman Foundation, New York, with an introduction by Oswald Jonas.

${ }^{7}$ In a letter to Schlesinger dated at Vienna November 13,1821, Beethoven remarked that "my first draft [for Opus 109] was written out in a more detailed manner than usual" ("mein Concept
} 
any substantial late sketching, it was likely contained in a preliminary draft, or Urschrift, of which only a fragment of the third movement survives. ${ }^{8}$

Whatever mysteries they offer, the holes in the sketch evidence detract in no way from the importance of the two adagio sections. My concern in this study is to incorporate what sketch evidence exists into an analysis that explores the significance of these sections within the first movement of Opus 109, supplementing and amplifying other scholars' analyses of the Vivace sections. This done, a preliminary critical evaluation of the movement - indeed, the whole sonata - as a structural, dramatic, and even philosophical entity, is possible.

$* \quad * \quad *$

It is by now well established that the melodic interval G\#-B - first heard, on two rhythmic levels, in the opening anacrusis and first measure (see Example 1) - is of crucial importance to Opus 109. Marston's is only the most recent exploration of Beethoven's projection of this melodic interval onto the larger structure. Lengthy published analyses of Opus 109 by Heinrich Schenker and Allen Forte discuss the matter in detail (Schenker 1913, 1926; Forte 1961); and Korsyn uses the Vivace sections as an example of the "principle of disclosure: something that is hidden is revealed", in the sense that remote and immediate structural levels interact (1983: 31). ${ }^{9}$ A chart first published by Schenker in 1926 (see Example 2) handily summarizes the role of the motive $\mathrm{G \# -B}$ as a structural kingpin that inspires action and provides unity in the first movement. ${ }^{10}$ There is no need to repeat here the many revealing conclusions of these scholars. It will suffice for

weitlaufiger aufgeschrieben als gewohnlich"'). Because of this preparatory Urschrift work, Beethoven did less than his usual amount of true composition at the autograph stage; hence the relative neatness of the Reinschrift. Some of the late compositional work that I posit in my text, if it was worked out on paper at all, may have been done at the Urschrift stage. Meredith 1985a: I, 146-149, has a translation and discussion of the November 13 letter: II, 26-29, has a transcription.

${ }^{8}$ Drafts for parts of Variations 2 and 3 of the third movement of Opus 109 are to be found on a single bifolio (four pages of twelve-stave paper) in Vienna, Gesellschaft der Musikfreunde, A 47. Meredith (1985a: I, 186) says that "the bifolio represents Beethoven's move from sketch to rough draft", adding that "it probably represents a rejected bifolio from the Urschrift, the remainder of which is unfortunately not extant." This bifolio, the letter quoted in Note 7, the condition of the Reinschrift, and internal musical evidence all point to the existence of an Urschrift, probably including all three movements.

${ }^{9}$ Korsyn's complete analysis of the first movement is found in 1983: $31-45$, in a section entitled "Interaction of Remote and Immediate Levels".

10 This chart was first published in Schenker 1926: 51 some 13 years after his original critical edition of Opus 109, which, in Korsyn's words (1983:33) "does not anticipate this extraordinary intuition." 

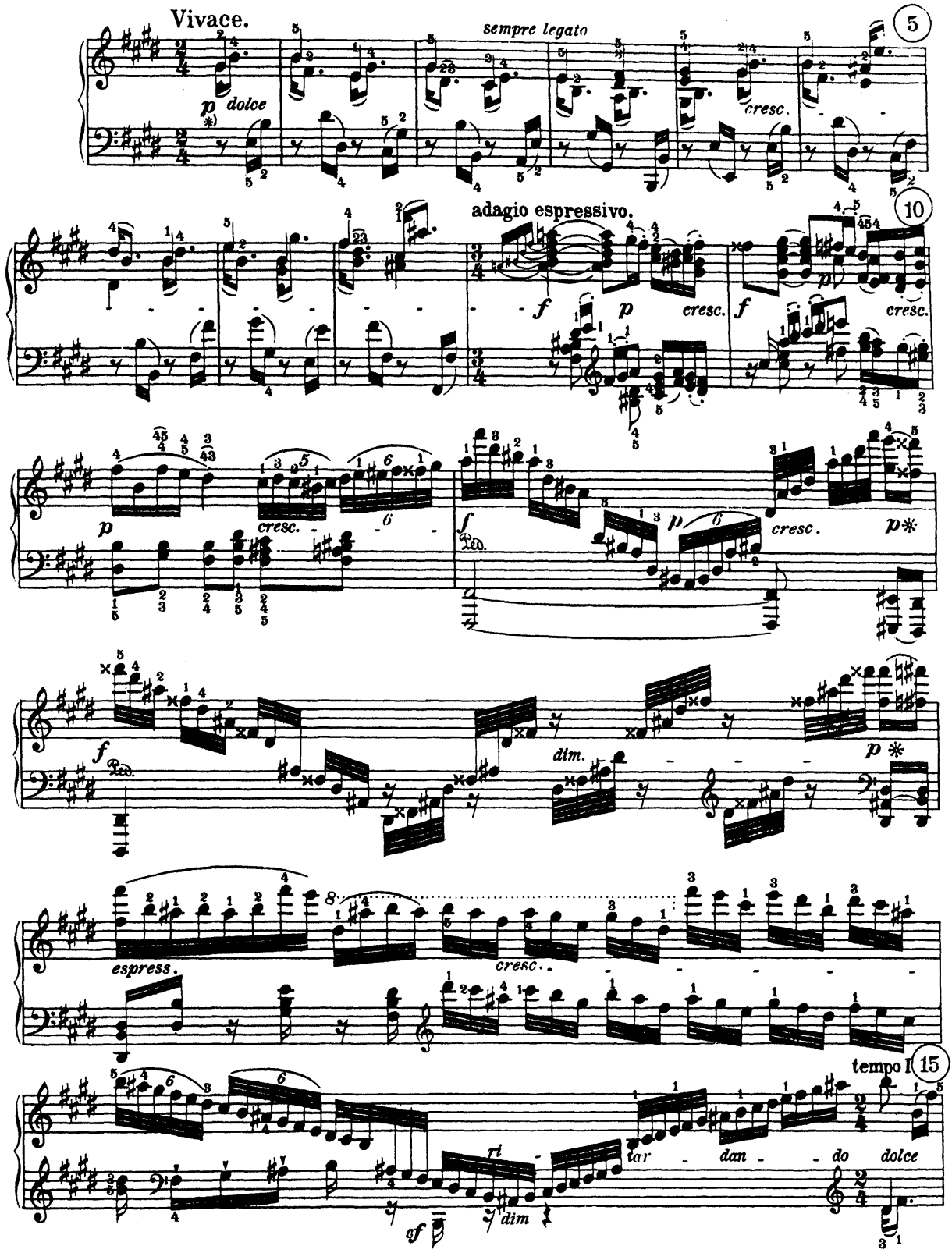

Example 1: Opus 109/, mm. 1-15 


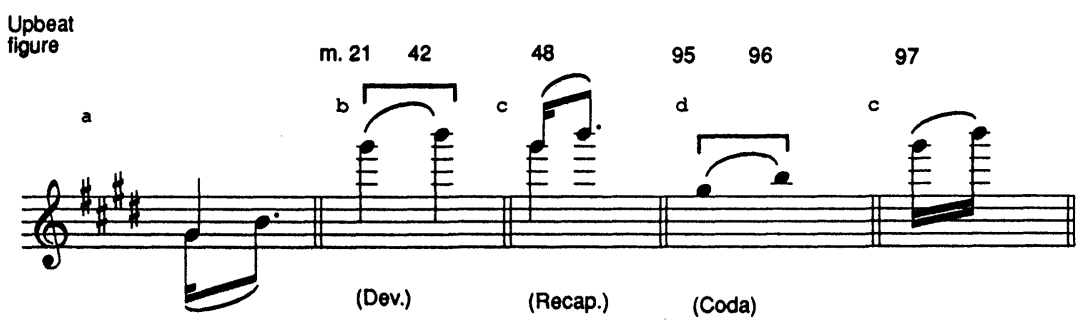

Example 2: Chart from Schenker, "Organischen"

my purposes to note that the basic tonic-dominant polarity of the first movement, and the most important melodic activity within it, are heard with reference to the controlling motive G\#-B, and that the notes which connect or decorate this motive ( $\mathrm{A}$ and $\mathrm{A \#}, \mathrm{C}$ and $\mathrm{C \#}, \mathrm{F \#}$ and $\mathrm{Fx}$ ) have long-range implications.

From even this brief account, it is apparent that the Vivace sections contribute an arching framework that binds the first movement together. The adagio sections (passed over in Schenker's chart) stand apart. Indeed, the first notable feature of the adagios is that they partake of that peculiar tendency in late period Beethoven toward parenthetical enclosure. (Other examples can be found in the Largo of the "Hammerklavier" Sonata, Opus 106 (Rosen 1972: 426-429), the first movement of the Piano Sonata in C Minor, Opus 111 (Kinderman 1988: 4851), and the Credo of the Missa solemnis (Kinderman 1985: esp. 105-108 and 113; Kinderman 1988: 43-45). The adagios could, with a little rewriting at the seams, be lifted whole from the surrounding texture, leaving a pleasant, perfectly intelligible, even tightly unified bagatelle. Yet they surely do more than break up the monotony. We sense intuitively that without them the movement loses its dramatic urgency. We are led then to ask how these sections function within the larger structure - how they are woven into the musical fabric.

The chart, along with relevant explanatory passages from Schenker's diaries and from "Organischen", is quoted in a footnote in the Jonas edition of Schenker 1913: 18-19. Marston (1986c: 25) quotes this material again, in his own translation. Extraordinary as the observation contained in Schenker's chart surely is, it did not inspire him to undertake a full and rigorous analysis. As Korsyn points out (1983: 33), "Schenker's remarks on op. 109/I in this article ["Organischen"] are quite laconic"; neither "do his references to this piece in Free Composition fully amplify this adumbrated commentary." Graphic analyses of parts of the development (mm. 15-21) and exposition (mm. 1-4) are given and briefly discussed in Schenker 1935: Figures 89/1 and 90; Figure 117/2 presents part of the score for the first adagio, but with no commentary. 
The first adagio grows out of the first appearance of conflict between A and A\#, the two possible notes of connection within the motive G\#-B. ${ }^{11}$ The tonal purity of the opening measures - in which, to use Marston's phrase (1986c: 28), the "Etonicizing" progression B-A-G\# appears in the bass (mm. 2-3) and in an inner voice (mm. 3-4) - is first ruffled by the melodic appearance of A\# in the treble in $\mathrm{m} .5$ (see Example 1). Mm. 5-8 move towards dominant modulation; the F\# Major chord in $\mathrm{m} .8$ definitely cues in B Major. But the expected modulation is broken off. The treble A\# resolves deceptively to A over a diminished seventh chord, and the tonality deflects momentarily toward C\# Minor. Only after seven measures of secondary dominants in a fantasy texture is the dominant modulation achieved. At the end of m. 15, the "B-tonicizing" (Marston 1986c: 28) progression G\#-A\#-B completes the modulation in the very register in which it was interrupted, and with the resumption of the arpeggiated Vivace texture, the development begins.

The adagio itself divides into two parts: three measures (9-11) harmonizing the basic melodic progression A-G\#-F\#, moving tentatively in the direction of B Major; and four measures (12-15) that vary this same process, now achieving B Major. Mm. 9-11 are harmonically straightforward, their improvisatory character notwithstanding. If we interpret the diminished seventh chord in $\mathrm{m} .9$ as a dominant minor ninth chord with an implied root G\# - an interpretation suggested by Beethoven's spelling of the chord, and by its audible effect as the dominant of the $\mathrm{C \#}$ Minor sixth chord in $\mathrm{m} .10$ - then these three measures imply a basic root progression by cycle of fifths, aimed at B Major (see Example 3; roots shown in parentheses). But both melodically and harmonically, the movement toward B is deferred again at the last minute. The melodic progression A-G\#-F\#, begun in $\mathrm{m} .9$, is thwarted in its attempt to continue descending to $B$ (hinted at in the second sixteenth note of $\mathrm{m}$. 11): it reaches $\mathrm{C \#} \mathrm{(decorated} \mathrm{with} \mathrm{B \# ),} \mathrm{in} \mathrm{m}$. 11 , then is deflected back up to $A$. In the same measure, the dominant F\# Major resolves not to B Major but to a diminished seventh chord, the move from A\# to $A$ in an inner voice renewing the source of tension that originally inspired the adagio at m. 9 .

11 The interval G\#-B offers two melodic options, both exploited, at different levels, in this movement: the rising progression G\#-A\#-B, and the descending progression B-A-G\#. Marston (1986c: 27) writes, "These two progressions encapsulate melodically a modulation from the tonic to the dominant, and from the dominant back to the tonic." Marston shows the long-range importance of these progressions (and thus of the notes $A$ and A\#) within the first movement. For one thing, these progressions connect the crucial G\#-B interval to the basic basic I-V tonal polarity of the movement. Indeed, we may have here the answer to why the secondary key of this movement is the old-fashioned dominant, rather than one of the third-related keys Beethoven was more partial to at this time: the tonal scheme is inextricably linked with the motivic material. 


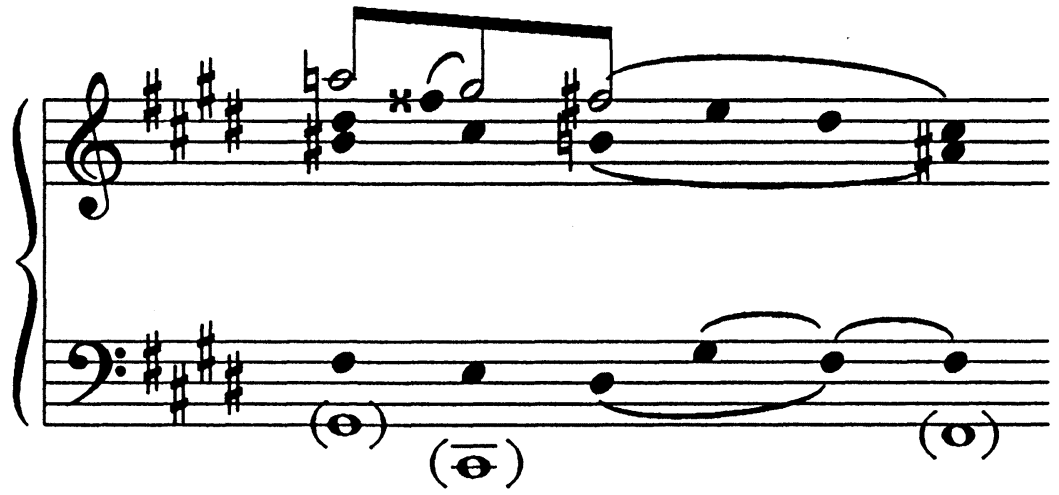

Example 3: cf. Opus 109/I, mm. 9-11

On the first page of sketches for this movement, Beethoven explored several fantasy-like continuations of the Vivace theme. ${ }^{12}$ The first of these sketches (see Appendix: Sketch 1) suggests three possibilities: an immediate resolution of the treble A\# to B (staves 5-7); retention of the tonic E Major (st. 7); and a modulation to the relative minor, C\# (st. 8-9). (The first option is sketched a second time on the same page; Sketch 2.) On the last staves of this sketch page, Beethoven first conceived the idea of a deflection from A\# to A (Sketch 3/st. 13); here, however, the gesture does not lead eventually to the dominant, but rather reaffirms the tonic. Meredith observes that in this sketch the quarter notes succeeding the deflection end on $\mathrm{E}$, "suggesting both that the original [Vivace] figuration continues to that point, and that the [note $\mathrm{A}$ ] is used to bridge the antecedent and consequent phrases of the first theme, not to lead into the fantasia [adagio] section"' (Meredith 1985a: I, 274).

On the second page of sketches, Beethoven decided on the melodic progression A-G\#-F\# as the basis for a florid second subject group (Sketch 4/st. 4), and in a lengthy continuity draft on the third page, he confirmed the design of this section as a series of secondary dominants preparing the modulation to B Major (Sketch 5). This basic outline changed little throughout the compositional

12 Both Meredith (1985b) and Marston (1986b) argue that what became the first movement of Opus 109 was in its earliest manifestations a short independent piece in the style of a fantasy, though they disagree on the external circumstances of the piece's conception, and on details of dating. Kinderman (1988: 46) adds himself, Hans-Werner Küthen, and Sieghard Brandenburg to the list of scholars who support the independent origin of this movement. 
process. The final form of $\mathrm{mm}$. 9-11 accords closely in structural essence with Beethoven's earliest and simplest ideas for this passage.

The sketches for mm. 12-15 show that Beethoven had decided from the start to vary the improvisatory texture of mm. 9-11, originally by melisma (Sketch 4/st. 4-6), only later settling on the final idea of arpeggios (Sketch 5/st. 5a-6a and Sketch 6). But in these sketches, the variant measures retain intact the progression A-G\#-F\# and repeat the basic harmonization implied in the sketches for $\mathrm{mm}$. 9-11. Thus Beethoven's original plan for the modulation to the dominant in the first adagio involved the melodic idea A-G\#-F\# twice harmonized by a cycle of fifths, with variation only in terms of rhythm and texture.

At some point in the compositional process - perhaps in work (now lost) at the Urschrift stage - Beethoven must have felt that he had not mined fully enough the possibilities of his adagio material. That $\mathrm{mm}$. 12-15 should repeat the harmonization of mm. 9-11 must have seemed pedestrian, especially in a passage conceived from the start as having the character of an improvisational fantasy. Also, in the last sketch version of mm. 12-15, Beethoven does not anchor the effusive arpeggios with decisive bass movement, a feature that, according to the final score, he would come to consider essential. (In Sketch 6, he seems to let the arpeggios dip randomly into the bass register, spelling the necessary chords and defining the texture, but not explicitly proposing any meaningful bass.) In the final score it is $\mathrm{m}$. 13 that departs most significantly from the model of mm. 9-11. The melodic note $F x(=G)$ replaces the G\# expected by analogy with $\mathrm{m} .10$, and is harmonized by a D\# Major chord. What accounts for this important and dramatic variation, which has no precedent in the extant sketches? ${ }^{13}$

First let it be said that, however surprising, D\# Major in $\mathrm{m} .13$ is not implausible or contrived; the voice-leading context in which it occurs is perfectly sound. Where he had resolved an implied G\# dominant minor ninth chord to C\# Minor in $\mathrm{m}$. 10, Beethoven passes through resolution to C\# (Major) at the end of $\mathrm{m} .12$

${ }^{13}$ Meredith (1985a: II, 124) transcribes as D\# Major an arpeggio on Grasnick 20b, leaf 4r, stave 6, which occurs amid sketches for the first adagio section in a continuity draft for the whole movement. This interpretation (of a passage admittedly hard to read in the original) requires the assumption of a sharp before a written $A$ and a double sharp before a written $\mathrm{F}$ - more editorial intrusion than I am prepared to make. Marston (1986a: III, 3) transcribes this arpeggio, more sensibly, as part of a progression moving from C\# Minor through a diminished seventh chord to B Major. Meredith's transcription begs the question of why Beethoven would have considered D\# Major early in the sketches for the first adagio only to abandon it (in favour of blander harmonizations) in later sketches and then return to it in the autograph. 
to D\# Major by chromatic voice leading. The use of the interval E\#-G\# alone to represent C\# Major smooths the flow to D\# Major. Further, the implied G\# root of $\mathrm{m} .12$ is a fifth away from D\# Major, and one can perhaps hear some sense of a I-IV relationship between the two chords; at least, this proximity of roots maintains tonal cohesion.

Closer analysis reveals that D\# Major, far from an arbitrary variant harmonization of $\mathrm{m} .10$, is in fact an intersection of three factors - namely Fx, A\#, and D\# - each of independent logic in $\mathrm{m}$. 13. The note Fx, substituting melodically for

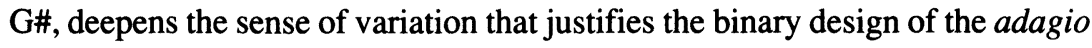
section, and also (as we will see in detail later) initiates an important long-range conflict between the notes $G$ and $G \#$. The note $A \#$, in an inner voice, reinstates the leading tone of B Major (averted in an inner voice in $\mathrm{m}$. 11) - appropriate given the urgency now of resolving definitively to the twice-deferred dominant. (The leading tone-to-tonic effect of A\#-B mitigates some of the strangeness of the direct move from D\# Major to B Major at the end of m. 13.) And the note D\#, in the bass, is part of an ingenious structural device that Beethoven incorporated at a (presumably) late stage of composition for which no sketches survive. The rhythm, dynamics, pedal markings, and lush textures conspire in mm. 12-15 to emphasize, with decisiveness wanting in the sketches, three notes in the lowest register: F\#-D\#-B, the very notes of the dominant triad. It is possible, then, to see the strange progression of $\mathrm{mm}$. 12-15 not only as a variation and dramatic intensification of the harmonic progression of $\mathrm{mm}$. 9-11, but as a composing out of the very triad to which this passage aspires. The music takes on another layer of meaning here, with the bass functioning melodically in the large quite apart from its simultaneous harmonic implications. (Note how the sforzando on the low B in $\mathrm{m}$. 15 audibly separates the melodic completion of the composed-out dominant triad from the harmonic arrival on the dominant in the high register on the downbeat of that measure; the melodic and harmonic functions are thus kept distinct and clarified..$^{14}$ ) Beethoven has mm. 12-15 perform double duty in the final score, variation incorporating added density of structure.

(Only after the period of the extant sketches - presumably around the time of the substitution of Fx for G\# in m. 13 - did Beethoven add the Fx appoggiatura to the melodic note G\# in $\mathrm{m}$. 10. He did, in a sketch for the parallel spot in the recapitulation, consider adding a preparatory embellishment to the melodic

\footnotetext{
14 The lowest B was not available on Beethoven's piano, and so the low B in m. 15 cannot complete the composing out with the perfect registral consistency that the lower octave would provide. (Did Beethoven perhaps intend the sforzando to make up for this octave?) Whether modern pianists should consider adding the "missing" lower octave to the low B here, clarifying its structural relationship to $\mathrm{mm} .12-13$, I would not presume to say.
} 
note, but only the lower octave (Sketch 7/st. 7). The final version of $\mathrm{m} .10$ is not only of local ornamental interest. Fx here ornaments, but then, in m. 13, replaces G\# (Forte 1961:21-22), and so the progression G\#-Fx at the end of m. 12 is heard as an inversion of the progression Fx-G\# in m. 10. As we shall see later, this seemingly inconsequential detail sets precedents for substitution and inversion that Beethoven exploits with significant consequences in the recapitulated adagio.)

We are now in a position to see that the first adagio section functions as a dramatic agent. As a parenthesis instigated by a deflection away from the ambitions of the opening material, it almost by definition distances itself from the explicit motivic argument worked out in the Vivace sections (that is, the structure based on the interval G\#-B). Rather, the adagio expands and comments on this argument, and just as a Greek chorus must not take part in the action, so this section, by an extreme shift in mood, tempo, and texture, is set apart. Suspended in a kind of harmonic no-man's-land on the brink of dominant modulation, the adagio develops the tension between the crucial notes $\mathrm{A}$ and $\mathrm{A \#}$ -between Marston's E- and B-tonicizing progressions. In contrast to the smooth modulation attempted in mm. 4-8, here the dominant key is discovered and unfolded, the constituent parts of its triad even composed out in the bass. ${ }^{15} \mathrm{We}$ saw that Beethoven had, in early sketches, considered the glib resolution of A\# to $\mathrm{B}$ in $\mathrm{m} .8$ likely to continue the Vivace texture, at least temporarily, in the dominant (Sketch 1/st. 5-7 and Sketch 2). But a modulation to B after only eight quick bars - some 10 seconds in performance - would have had little weight or urgency. Beethoven expresses this view emphatically in a later sketch, in which he first repeats the resolution of A\# to B, but then crosses it out and inserts the deflection to A (Sketch 8/st. 1 and 4). ${ }^{16}$ The adagio checks the modulatory

\footnotetext{
${ }^{15}$ Hence the logic of Beethoven's unusual delaying of the dominant modulation until after the completion of the second subject group. As Kinderman (1988: 48) notes, "the second theme of the exposition of this sonata movement is not adequately understood as simply the contrasting continuation to a first theme of unusually brief or compressed proportions. Instead, the second theme is enclosed here within the first theme, whose direct continuation after completion of the cadence to B major leads organically into the development section." The notion of the second theme "enclosed" within the first has important critical implications. It is consistent with my observations here on the function of the first adagio as an expansion and commentary on the goals of the Vivace, and with my concluding discussion of dialectic in Opus 109.

${ }^{16}$ While Meredith's transcription of the passage in Sketch 8 accords with mine, I believe that he misreads the intentions behind Beethoven's excision. In his discussion of this passage (1985a: I, 277280 ), Meredith suggests that Beethoven had planned here to first resolve A\# to B, then, a bar later, to deflect to $\mathrm{A}$ - in other words, that rather than resolve to $\mathrm{B}$ or deflect to $\mathrm{A}$, Beethoven intended to do both, negating the one with the other. I believe that the explanation is simpler: Beethoven first followed A\# with B, perhaps without thinking (he had resolved A\# to B in two early instances; see
} 
precocity of the opening material, and provides that period of reflection that gives the dominant goal its importance.

Interesting in this regard are the comments of Wilfrid Mellers, who, in his provocative book Beethoven and the Voice of God, finds in the first and second subjects "musical synonyms for the states Blake called Innocence and Experience" (Mellers 1983: 200). (I will have more to say on the dialectical implications of such an idea later.) Beethoven is not content to leave the naïveté of the opening measures unchallenged, the modulation not fully worked out. The two-stage, statement-variation structure of the adagio, with its steady accumulation of tension, gives great emphasis and psychological depth to the final achievement of the dominant modulation, making it the more significant because the more hard-won. Like the Largo of the "Hammerklavier" Sonata or the "recitatives" in the Piano Sonata in A-flat Major, Opus 110, this adagio is a dramatic process of reflection and discovery. It makes a sonata of a bagatelle.

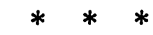

Schenker's chart, quoted in Example 2, reveals in broadest outline the structure of the development section as a composing out of the interval G\#-B: the two main harmonic goals of this section are G\# Minor (m. 21) and B Major (m. 42), both reached in the very highest register. ${ }^{17}$ This has been further discussed by other writers (Schenker 1913: 14-19; Forte 1961:22-23 and 32-38; Korsyn 1983: 3337 and 41-43; Marston 1986c: 29-31). (The two-stage structure of the development section is, incidentally, neatly reflected in its two-stage compositional genesis. ${ }^{18}$ ) The B-tonicizing progression G\#-A\#-B, heard at the very end of the adagio, appears in the development ( $\mathrm{mm}$. 26-27, etc.), contributing to the

Sketches 1-2), then immediately corrected himself by excising the B, backtracked a few beats, and sketched the deflection A\#-A. As Beethoven had clearly settled on the deflection A\#-A earlier (see Sketch 5), the process of thought Meredith suggests makes little sense at this point. (Meredith himself points to the weakness of Sketch 8 as he interprets it.)

${ }^{17}$ Korsyn (1983: 33 ) refers to the high dominant pedal of mm. $42-48$ - the highest note of the movement - as a "registral ceiling".

${ }^{18}$ The rather vague work on the development section in Grasnick $20 \mathrm{~b}$ was supplemented by work in a later pocket sketchbook: BH 107, Beethoven-Haus, Bonn, SBH 665, which contains sketches for the first movement of Opus 109 on pp. 39-41 and 43. The sketch leaf BSk 27/75, BeethovenHaus, Bonn, originally belonged to $B H 107$, between pp. 42 and 43; it contains a short sketch for the development section. In Grasnick 20b, Beethoven sketched a development section that concluded with the dominant of $\mathrm{C \#}$ leading directly into the tonic recapitulation (see leaf $4 \mathrm{v}$, staves 11-16, and its continuation on 5r, stave 1). Only in the pocket sketches did Beethoven decide to continue the development section from the $\mathrm{G} \#$ Major cadence to a dominant (B) pedal announcing the recapitulation, completing the large-scale composing out of the interval G\#-B. 
accumulation of sharpward harmonic tension. After m. 42, with the achieved high $\mathrm{B}$ used as a dominant pedal, A\# gives way to A (and, by implication, to the E- tonicizing progression B-A-G\#), heralding the return of the tonic key and the recapitulation. We can see in the development that the conflict of the notes $A$ and A\#, which instigated the first adagio, continues to play a key role in the structure. Further, the linear melodic figures that begin to infiltrate the arpeggiated texture in the development (as in mm. 22-24) suggest a spilling over of adagio material into the Vivace - setting the stage for an eventual tentative union of the two in the coda. ${ }^{19}$ In both cases, we begin to see how the adagio section functions within, and even influences, the structure of the rest of the movement.

The high B pedal leads to the recapitulation at m. 48. As Korsyn points out, the G\#-B interval in the high register, with which the recapitulation opens, encapsulates the composing out of that interval that has been the raison d'être of the development: "the appearance of the reprise in this register not only summarizes the events that have unfolded in this register over such a long span, it also makes the thematic association of these events explicit" (Korsyn 1983: 43). The structural importance of G\#-B is made clearly audible.

The recapitulation of the opening Vivace material (mm. 48-57; see Example 4) is regular, save alterations of texture: the melody continues in the high register, while the bass plunges forte in octaves through the E Major scale in the low

${ }^{19}$ Carl Dahlhaus goes farther, finding such linear material the main locus of unity for Opus 109. In his discussion of this sonata (1991: 213-215), Dahlhaus conspicuously says nothing about the unifying function of the G\#-B motive discussed by so many other analysts; he seems unaware of the idea, or else ignores it outright. But he finds it difficult to see a key to structural unity without it. It is almost reluctantly - "The analyst is therefore left with no other choice but ..." (1991: 214) - that he finds the descending octave progression outlined in the bass in mm. 1-4 the "true" theme of Opus 109. Dahlhaus has a point: the descending bass is common to the opening themes of the first two movements, and so the rising bass that underlies the theme of the last movement can be heard as a kind of response to the descending bass - consistent with the resolving, synthesizing function of this movement. Further, the linear components Dahlhaus finds in the arpeggiated Vivace material link it more closely with the melodic adagio material; here is a "subthematic" connection between the two theme groups, balancing their outward differences. (All of this accords with my observations about the two theme groups infiltrating each other's space as the movement progresses, and reaching some kind of union in the coda; Dahlhaus's observations fit into my later conclusions about the dialectical implications of Opus 109, too.) But to me, the admitted tentativeness of Dahlhaus's analysis of 109 in the absence of the G\#-B motive only confirms importance of that motive. When Dahlhaus observes (1991:214) that "the association with the stepwise progression in the bass offers the only chance of enabling the development, in so far as it is one, to be comprehensible as such," he is conspicuously ignoring Schenker's original interpretation of the development and the later commentaries on it; but he offers nothing more convincing in its place. Valuable as Dahlhaus's observations on Opus 109 are, they seem to miss the real ordering principle of the work, and exaggerate the importance of a secondary element of the structure. 
Example 4: Opus 109/I, mm. 48-65

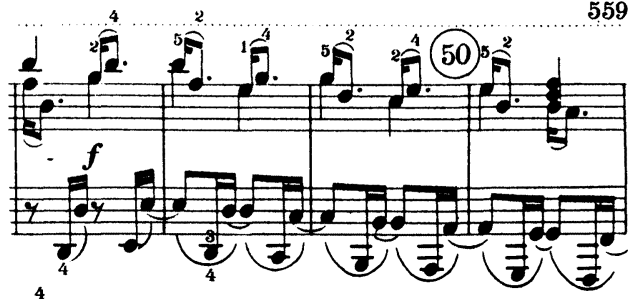

(2)

adagio espressivo.

$\widehat{45}$

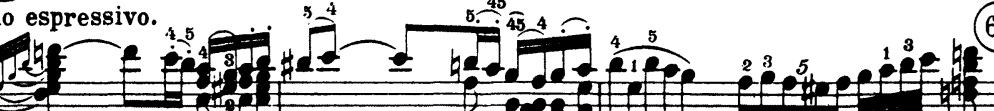

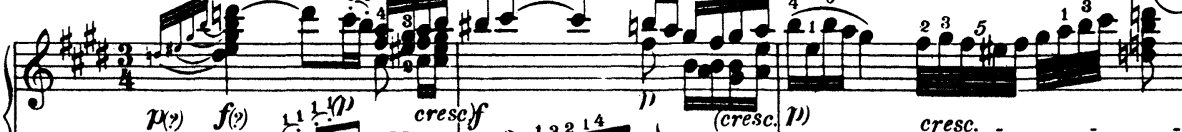

$\mu(:)$
$f(:)$

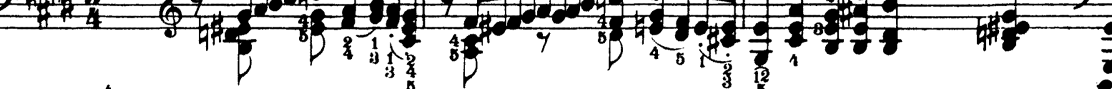

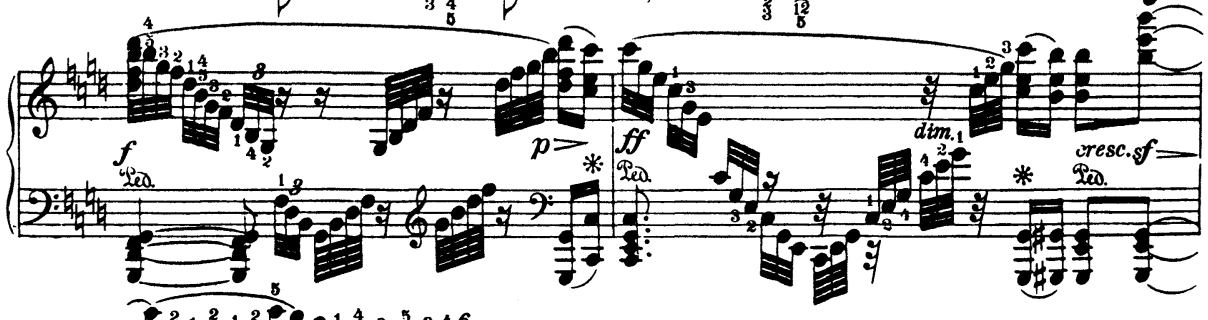

至:

(a)

2010

20.

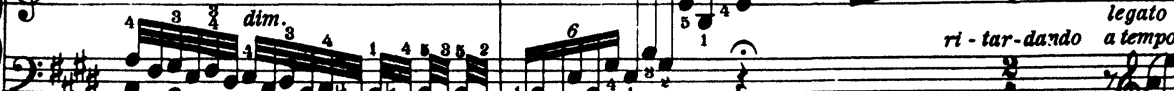

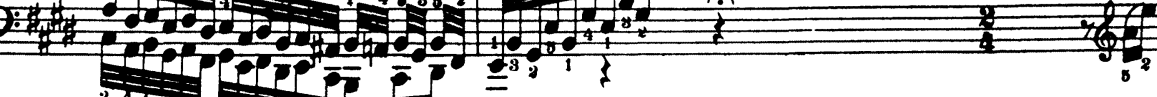

24121, 


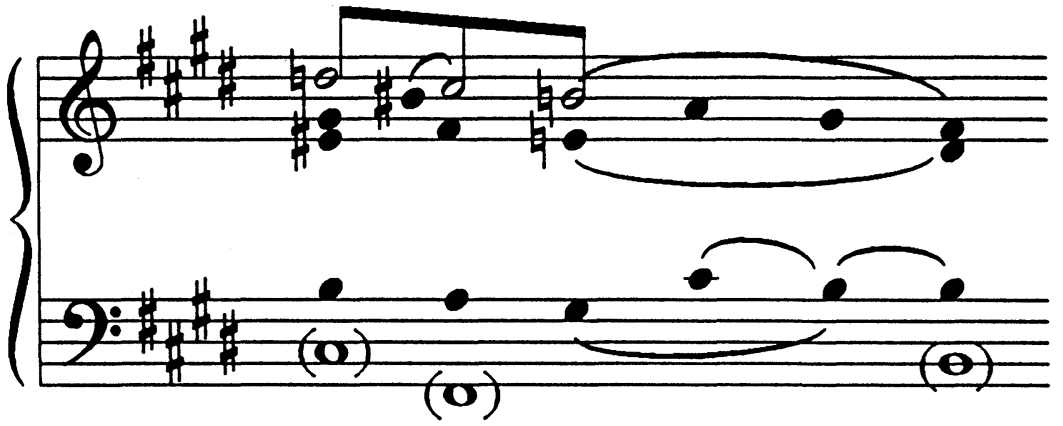

Example 5: cf. Opus 109/I, mm. 58-60

register. An added bar maintains the tonic through $\mathrm{mm}$. 52-57; in $\mathrm{m} .57$, by analogy with the exposition, the $\mathrm{D \#}$ in the treble seems to cue in $\mathrm{E}$ Major, but resolves deceptively to $\mathrm{D}$, and the adagio espressivo is recapitulated.

In spite of its protean character, the first movement observes strictly the usual formal divisions and tonic-dominant polarity of the textbook sonata-allegro. (Tovey's description - "terse but free sonata form" - cannot be bettered (Tovey 1972: 1,031).) Given this outward adherence to Classical formal and tonal procedures, we come to the second adagio with certain expectations of the recapitulation of analogous earlier material.

We expect first that the tonal path of the first adagio-modulation to the dominant - will be resolved by a reaffirmation of the tonic, and, as a corollary, that the main melodic progression of the first adagio, A-G\#-F\#, will be resolved up a fourth to D-C\#-B. This is in fact the case in mm. 58-60, which match almost exactly the analogous mm. 9-11 (see Example 4). Again, the spelling of the diminished seventh chord in $\mathrm{m} .58$, and its audible effect as the dominant of the following F\# Minor sixth chord (m. 59), suggest a dominant minor ninth chord, now with an implied root $\mathrm{C \#}$. And so here a root progression by cycle of fifths offers an exact rhyme to that of the exposition, now moving toward E Major (see Example 5). However, the variation of these bars (that is, mm. 61-65) departs from this model even more radically than the corresponding passage in the first adagio. Moving for a moment to the far-flung tonality of C Major ( 4 VI)-even changing the key signature to clarify the point - the music takes on a second layer of parenthesis, and a climax is achieved in a passage marked by the only fortissimo of the movement.

Beethoven's one significant sketch for mm. 61-65 shows a much more straightforward structural relationship to $\mathrm{mm}$. 58-60 than is the case in the final score. (In this respect, this sketch is in accord with the sketches for the first adagio.) Beethoven originally considered repeating in mm. 61-65 the cycle of fifths 


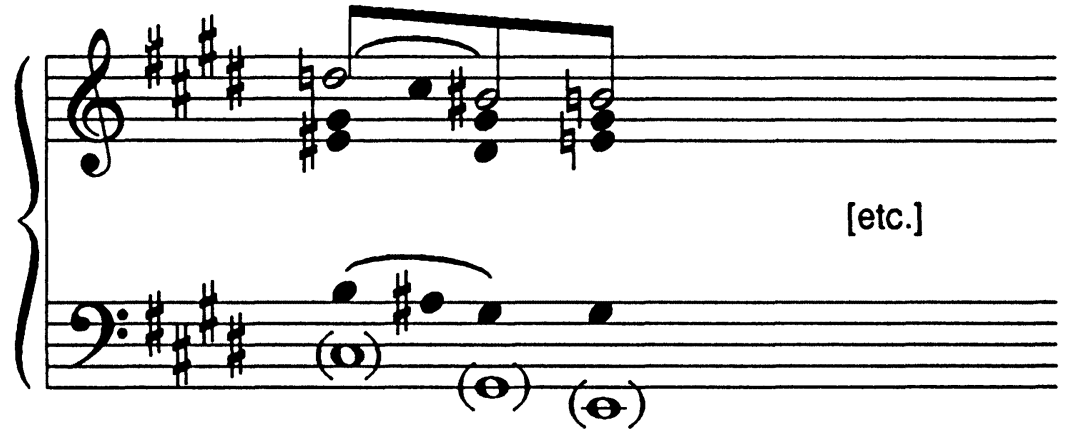

Example 6: cf. Opus 109/I, mm. 61-65 (hypothetical)

harmonies of mm. 58-60, changing only the texture (Sketch 9). But just as the exposition sketches for $\mathrm{mm}$. 12-15 are unsatisfactory, this sketch for the analogous passage is even more so. The problems of harmonic redundancy and the absence of an anchoring bass remain. And the vague diminished seventh chords offer no possibility of solid tonic confirmation - surely a concern for Beethoven at this point in a recapitulation. Further, there is no sense in Sketch 9 of a firm resolution of the conspicuous sharpward harmonic bent of the movement to this point. And finally, the very elements of strangeness and surprise that characterize mm. 12-15 imply new surprises here. As much as the first movement of the "Hammerklavier" Sonata, here is a movement that seems to demand a climax after the point of recapitulation (see Rosen 1972: 414).

In composing the final version of mm. 61-65, Beethoven's foremost problem was that, while the movement's outward adherence to Classical principles calls for symmetrical tonic recapitulation of the adagio material, the elements of required recapitulation are at variance with each other. Given that the dominant triad (F\#-D\#-B) was composed out melodically in the bass in mm. 12-15, we expect in mm. 61-65 an analogous composing out of the interval that acts as the correct resolution to this triad, namely G\#-E. (Since Beethoven projects a locallevel phenomenon - the dominant triad - in the first adagio, he sets up the expectation of a resolution according to rules of proper local voice leading, a resolution that will be composed out on the same scale and in the same register as before.) Further, we expect that the melodic variant in mm. 12-15 (the progression A-Fx-F\#) will be resolved up a fourth to D-B\#-B. Having abandoned his simplistic sketch for mm. 12-15 for the more unusual final version, Beethoven found himself in the second adagio at a point where the demands of resolution of bass and melody conflict not only with each other, but with the need for a decisive grounding of the tonic key. To have exactly resolved up a fourth the entire harmonic plan of mm. 12-15 (see Example 6) would have resulted in an 
unacceptable progression that would only have undercut, rather than confirmed, the tonic recapitulation begun at $\mathrm{m} .48$.

But there are even further problems. If he accepted, as the precedent of his exposition suggested, that the function of the bass in mm. 61-65 was to resolve the triad F\#-D\#-B to G\#-E, Beethoven must have found himself - simplistic as it sounds -with time to fill. The composing out of F\#-D\#-B was a three-stage process involving three harmonies, parallel to the melodic progression $\mathrm{A}-\mathrm{Fx}-\mathrm{F \#}$. In mm. 61-65, however, Beethoven would have found himself with a three-stage melody (D-B\#-B) and a two-stage bass progression (G\#-E) which, superimposed, seem utterly inconsistent with a meaningful confirmation of the tonic $\mathrm{E}$ Major, without which the recapitulation would founder. With an unacceptable (indeed, banal) sketch for mm. 61-65, and with melodic and harmonic elements in these measures resisting easy synchronization, Beethoven must have asked himself at some late stage of composition how effectively to juggle the various demands of recapitulation, resolution, climax, and surprise.

His solution, characteristically, is brilliant. The $\mathrm{C}$ Major interpolation in mm. 61-62 does firmly harmonize the melodic notes D-C (=B\#). Furthermore, being a second layer of parenthesis, it stands far enough apart from the context of E Major to allow the bass progression G\#-E to be heard on a larger level. The low G\# bass at the end of m. 60 , unstably harmonized by a diminished seventh chord, moves by chromatic step to G; after the C Major arpeggio, the low $\mathrm{G}$ moves chromatically back to $\mathrm{G} \#$, this time harmonized by E Major and emphasized by a sforzando. The unhampered progression from first inversion to root position tonic in mm. 62-65 completes the bass progression G\#-E in the lowest register and solidifies the tonic. (The melodic composing out and the harmonic arrival are now coterminous, unlike in the first adagio.) Example 7 shows the basic functions of the bass in both mm. 12-15 and 60-65.

Given the magnitude of the explosion of $\mathrm{C}$ Major, it may seem at first unreasonable to posit the progression G\#-E as important bass activity in mm. 60-65, even if it makes good sense as a symmetrical recapitulation. Yet Beethoven takes special pains to set off the $\mathrm{C}$ Major parenthesis as a parenthesis, forcing it to stand apart from the music around it. The change of key signature was already mentioned. The chromatic slide from $\mathrm{G} \#$ to $\mathrm{G}$ in $\mathrm{mm}$. 60-61, and then the exactly inverted movement back to $\mathrm{G \#}$ in $\mathrm{m}$. 62 , very audibly frame this passage. Beethoven underscores the parenthesis even more with a rhythmic alteration from the analogous passage in the exposition: the last chord in $\mathrm{m}$. 60 introduces the low bass octave one eighth note "too early", by analogy with mm. 11-12; and the return to the G\# bass is a quarter note "too soon" in $\mathrm{m}$. 62, by analogy with $\mathrm{m}$. 13. In this way the C Major episode is conspicuously framed rhythmically, 


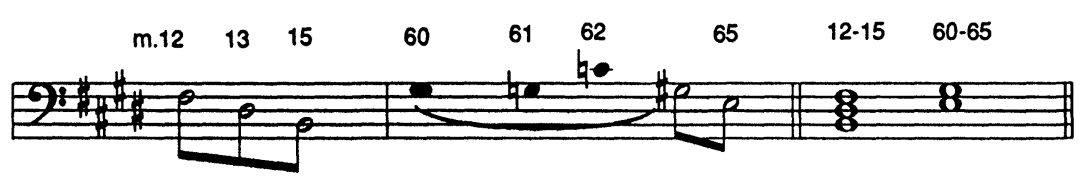

Example 7: cf. Opus 109/I, mm. 12-15 and 60-65

too. These rhythmic changes also create a greater urgency here than in the exposition, appropriate to this climactic moment: the melodic melisma in m. 60 must now be compressed into the space of one eighth note, and the arpeggio in m. 62 must be fitted into the space of a dotted quarter. (Note also the new urgency of inner voice activity in $\mathrm{m} .59$.)

It is clear that Beethoven fulfills in mm. 61-65 the demands of symmetrical tonic resolution of $\mathrm{mm} .12-15$. But the $\mathrm{C}$ Major episode is not significant merely for standing aside from this activity. It has of itself importance that confirms the genius of this solution to a compositional impasse.

For one thing, the $\mathrm{C}$ Major interpolation throws open the whole area of flatward relationships, and is therefore crucial to the tonal balance of the entire movement. As already mentioned, the movement has, to $\mathrm{m}$. 61 , been conspicuously sharpward tonally, moving as far in that direction as D\# Major/Minor and its dominant (mm. 25-32). The C Major of mm. 61-62 drastically shifts weight across the tonal fulcrum, as though it were a call for tonal balance - a call to order. ${ }^{20}$ Boldly reaching across the cycle of fifths, it balances the development's sharpward movement, cushioning the final acceptance of E Major. We might see Beethoven here as changing the course of the music by sheer force of will, just as he does at the point of recapitulation in the second movement of Opus 109. The climactic V-I fortissimo gesture, standing far outside the principal tonality, in the "white" key of C Major, acts as a kind of metaphor for tonic-dominant resolution in the abstract, calling for final resolution of the movement's basic I-V tonal polarity. And significantly, the music that follows is the resolution to the tonic of the last remaining exposition material. As a flatward force, the $\mathrm{C}$ Major gesture can be heard as the inspiration for the drop to the subdominant, A Major, in the coda. Its effects even spill over into the second movement, which is in $\mathrm{E}$ Minor (thus with $\mathrm{a}$ G and a $\mathrm{C}$ in its scale) and which is strongly plagal in tonal orientation. ${ }^{21}$

\footnotetext{
${ }^{20}$ Mellers (1983: 205) writes of this passage that "[d]ramatic forcefulness hints that the fusion of contrarieties that had not occurred in the exposition may be immanent".

${ }^{21}$ By analogy, see Rosen's observation (1972: 418) of "an overflow from the later tension into every corner of the work" in the "Hammerklavier" Sonata.
} 

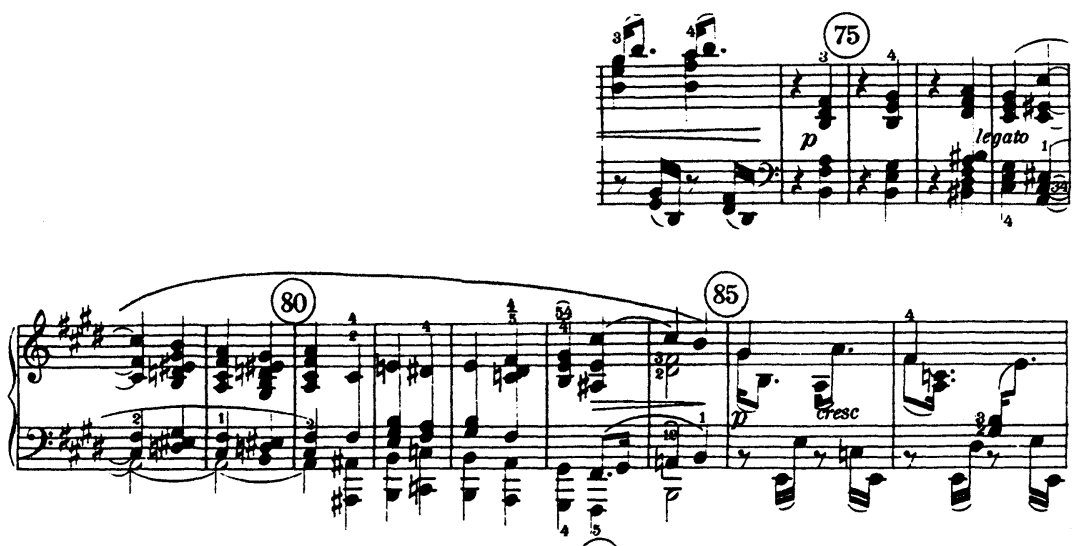

(90)
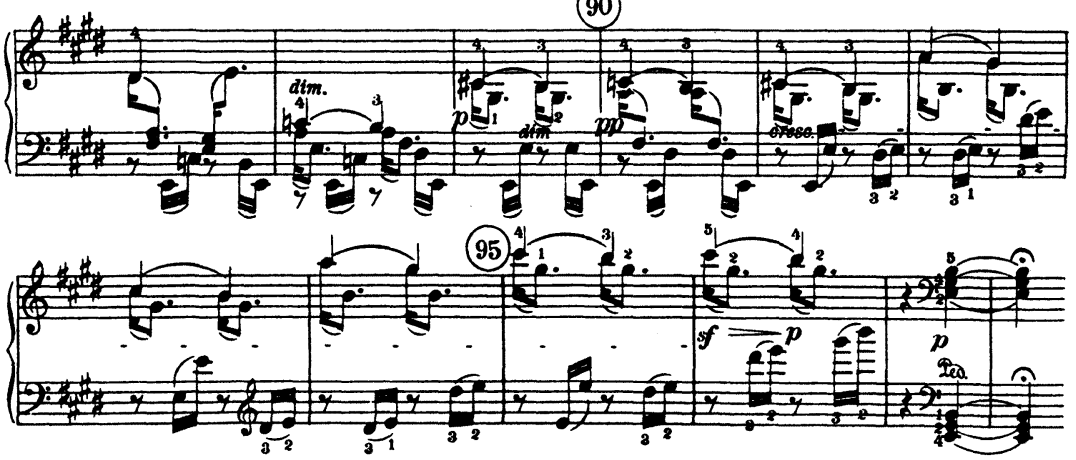

Example 8: Opus 109/1, mm. 74-99

The sudden appearance of $\mathrm{C}$ Major in the context of $\mathrm{E}$ Major also implies

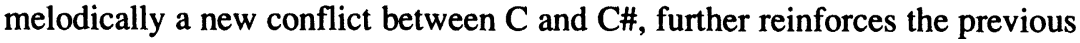
conflicting note pair G-G\#, and complements the original A-A\# conflict. The after-effects of the new C-C\# conflict can be heard in the coda (mm. 89-92; see Example 8), and even in the second and third movements. Such conflicts of note pairs are, as we shall see, important units of effect in this movement, punctuating the structure at several levels.

Early in the compositional process, Beethoven considered using C Major as a secondary key area, though not with its final climactic effect. The second page of sketches includes two short, isolated sketches for chains of trills sliding chromatically from B Major to the dominant seventh of C (Sketches 10 and 11). At this point, the movement had not yet taken on the thematic and tonal characteristics of a sonata-allegro, and the chains of trills were likely part of a free 


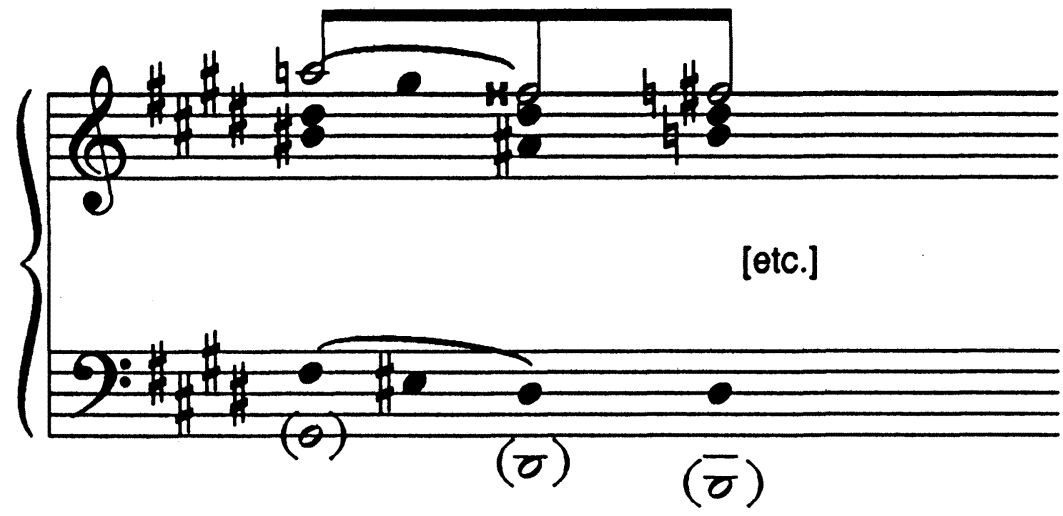

Example 9: cf. Opus 109/, mm. 12-15

fantasy that was to grow out of the opening Vivace material; an earlier sketch shows chains of trills within the tonal area of E Major/C\# Minor, immediately succeeding the opening arpeggios (Sketch 12). In a later continuity draft for the whole first movement, Beethoven inserted the chains of trills leading to C Major into the recapitulated adagio, at approximately the same spot occupied by $\mathrm{C}$ Major in the final score (Sketch 13). Connecting material is missing, however, and at this point the draft ends. Beethoven clearly had not yet determined how his early idea of $\mathrm{C}$ Major might function in the context of the recapitulation in a sonata movement in $\mathrm{E}$ Major. The gradual discovery of C Major's dominant certainly seems an arbitrary, even irrelevant, gesture in the harmonic environment of the draft for mm. 61-65. When he later came to require a special gesture of climactic forcefulness at this point, Beethoven must have seen $\mathrm{C}$ Major granted a change of texture - in a more viable light. Now pouncing upon the listener, rather than introducing itself urbanely to him, the key of $q \mathrm{VI}$ in the final score makes perfect sense.

The parenthetical nature, dramatic function, harmonic implications, and compositional genesis of the $\mathrm{C}$ Major climax should now be clear. But it remains to be seen whether this passage is as entirely unprecedented as it at first sounds. I believe that it is not - that it is, in fact, subtly integrated into the structural fabric of the whole movement, precisely prepared and explained.

I believe that, in mm. 61-65, Beethoven takes the precedents for melodic substitution and inversion in the first adagio and projects them onto the harmonic plan. The fundamental root progression of $\mathrm{mm} .12-15$ is summarized in Example 9. 


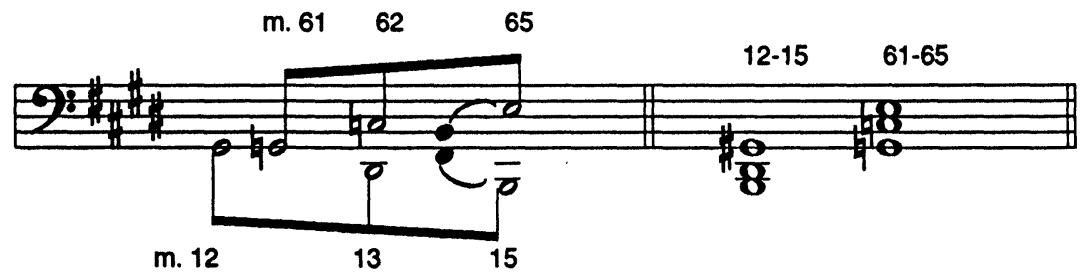

Example 10: cf. Opus 109/1, mm. 12-15 and 61-65

As we saw above, the assumption of the root $\mathrm{G} \#$ is substantiated by the spelling of the diminished seventh chord and by its audible effect as the dominant of C\# Minor (m. 10) and Major (m. 12). In spite of the dynamic and registral power of the F\# bass in $\mathrm{m} .12$, and its part in the composing out of the dominant triad, the diminished seventh chord in $\mathrm{m} .12$ functions harmonically as a dominant minor ninth chord with an implied root of G\#. We can therefore see that the relationship between the above root progression and that of $\mathrm{mm} .61-65$ is one of inversion (see Example 10).

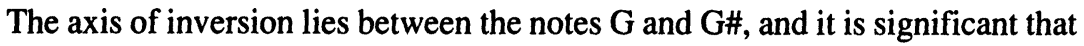
it is precisely these two notes that, in the first adagio, are treated as interchangeable. This interchangeability Beethoven takes as a precedent that he now develops in a surprising new way. Just as $\mathrm{G}(\mathrm{Fx})$ was permitted to stand in for $\mathrm{G \#}$ melodically in $\mathrm{m}$. 13, so the $\mathrm{G}$ chord of $\mathrm{m} .61$ stands harmonically in the place occupied by a chord with a fundamental root $\mathrm{G} \#$ in $\mathrm{m}$. 12. We have already seen that a recapitulation of mm. 61-65 that exactly accorded with $\mathrm{mm}$. 12-15 a fourth higher would have resulted in an unsatisfactory progression in every respect; the G\# Major chord this would have implied at $\mathrm{m}$. 62 would have been especially ineffective. Now we can see that Beethoven sidesteps this problem by eschewing recapitulation in $\mathrm{m} .61$ (which would have implied a diminished seventh chord with a bass note $\mathrm{B}$ and an implied root $\mathrm{C \#}$ ) in favour of substitution. Projecting the device of melodic substitution used in $\mathrm{m} .13$ onto the harmonic plan of the second adagio, Beethoven creates a surprising harmonic twist that is nonetheless logical in retrospect. The chromatic descent from $\mathrm{G} \#$ to $\mathrm{G}$ in the bass in $\mathrm{mm}$. 60 61 , and the answering ascent back to $\mathrm{G \#}$ in $\mathrm{m}$. 62, encapsulate the device of substitution in an immediately audible way, framing the relevant passage while giving the listener a clue as to its technical foundation. We see now that, as much as it interrupts and redirects the drama of the first movement, the $\mathrm{C}$ Major parenthesis helps tie the movement all the more tightly together. And having explored the two adagio sections in terms of subtle and cunning structural relationships, we are a long way from viewing them as merely fantastical.

The relationship of $\mathrm{G}$ and $\mathrm{G \#}$ in the two adagios is not only one of substitution, 
but also one of inversion: just as the melodic progression Fx-G\# in m. 10 is inverted as G\#-Fx at the end of m. 12, the descent G\#-G in mm. 60-61 is answered in $\mathrm{m}$. 62 by G-G\#. In fact, the very order of appearance of these note pairs in the second adagio inverts that of the first! If Beethoven worked out these relationships on paper he must have done so late in the compositional process, as the extant sketches do not reveal them. I suggested above that the ornamental Fx in $\mathrm{m} .10$ was a late compositional idea. Having now examined both adagios, I think it reasonable to suggest that Beethoven worked out the whole complex of substitutions and inversions involving the notes $\mathrm{G}$ and $\mathrm{G \#}$ at once - indeed, that precisely this was his way out of the compositional problems that he faced in the last of his surviving sketches. In doing so he was able to integrate, at a nuts-andbolts level, the adagio material, including surprises like $\mathrm{C}$ Major, into the basic structural fabric of the Vivace material - inner unity balancing outer variety. Discovering and developing ideas latent in his expository material - even building a structure around them - is certainly a characteristic if not predictable compositional procedure for Beethoven in his last years.

In mm. 63-65 the tonic is confirmed: an added bar of E Major arpeggios helps ground it solidly. The coda (mm. 66-99; see Example 8) renews the arpeggiated Vivace texture. It opens in the subdominant and is infused with the soft plagal effects that typically colour the confirmation of the tonic in Classical codas. The adagio sections are fleetingly recalled a final time in a hymnal passage in $\mathrm{mm}$. 75-85; in this passage - more explicitly than in the linear references in the development - Beethoven "resolves" the adagio texture into the Vivace. (It is interesting that this passage opens with the melodic progression F\#-G\#-A, the exact inversion of the main melodic progression of the first adagio.) To begin with, something of the implied cycle-of-fifths activity of the first adagio is briefly recalled (mm. 77-79). Melodic conflicts of earlier sections - A/A\# and $\mathrm{C} / \mathrm{C \#}-$ are recalled, and resolved in favour of the diatonic notes $\mathrm{A}$ and $\mathrm{C \#}$ : the treble $C \#$ in $\mathrm{mm}$. 84-85 supplants the bass reference to $C$ in $\mathrm{m}$. 82, while the low $A$ in $m$. 85 replaces the tenor $A \#$ of the previous measure. Thus $A \#$ and $C$, which had earlier been factors in modulations to $\mathrm{V}$ and $q \mathrm{VI}$, respectively, are finally resolved to the tonic. (Note that whereas the deflection A\#-A in the exposition led eventually to the dominant modulation, in $\mathrm{mm}$. 84-85 the cross relation now implies an affirmation of the tonic.) We can also consider G\# to have "won out" over its substitute, $\mathrm{G}$, in this final confirmation of the tonic. The peroration of E Major in mm. 86-99 stresses the diatonic notes $A$ and $C$ as upper neighbours to the crucial interval G\#-B (the "triumph" of C\# over C made explicit in mm. 89-92). The hymnal section therefore eliminates the last vestiges of the structural tension of the adagio sections, removing the last barriers to a conclusion whose diatonic repose matches that of the opening. 
Yet, as Marston and Korsyn have pointed out, the movement is in fact openended (Marston 1986c: 31-36; Korsyn 1983: 209-214). The closing bars are saturated with the rising interval G\#-B, which seems to imply the possibility of renewed dominant tension, suggesting that the tonic resolution of the first movement may be tentative in larger terms. Marston and Korsyn show convincingly, I think - that Beethoven intended a definitive resolution of the first movement only in the final movement; both analysis and compositional genesis suggest a structural affinity between the G\#-B motive in the first movement and the theme of the third. In Korsyn's words, "What the final movement of this sonata does is to realize the implications of the beginning of the first" (Korsyn 1983: 211). ${ }^{22}$ The final pedal marking - very clear in Beethoven's Reinschrift links the last tonic triad of the first movement to the E Minor Prestissimo scherzo that follows, creating a false relation G\#-G (another manifestation of that important note pair) and so pointing the way to a renewal of structural tension that only the closing theme and variations fully dissolves.

The analysis presented above suggests that we cannot fully understand the two adagio sections in Opus 109 without recourse to some very recondite structural details. I suggested that a composing out of the dominant triad and its resolution provided one source of structural cohesion between the two adagio sections, and I used this observation to speculate on some of the compositional problems Beethoven faced; yet no sketches or other documents prove conclusively such an interpretation. I intend my analyses to be defensible musically, and to make sense of some strange features in the score, but I cannot pretend that they would have Beethoven's blessing.

We are led inevitably to wonder to what extent the entire network of subtle relationships that we can see in the first movement of Opus 109 is the outcome of conscious compositional decisions by Beethoven. Put simply, am I inferring more structural unity than was intended?

Consider two possible interpretations. Having discovered in the first adagio a harmonic root movement from $\mathrm{G \#} \mathrm{(implied)} \mathrm{in} \mathrm{m} .9$ to $\mathrm{B}$ in $\mathrm{m} .15$, should we hear

${ }^{22}$ Korsyn's succeeding explanation of the synthesizing function of the third movement (1983: 211214) does not exactly accord with Marston's. John Rothgeb (1987: 295) replies to Marston's comments on the subject in $1986 \mathrm{c}$ by suggesting that the idea of the "incompleteness" of the first movement is based on Marston's mistranslation of a crucial passage in Schenker 1913: 25. Rothgeb argues that Schenker did not mean - as Marston suggests (1986:24) - that "the end of the movement is incomplete", but merely that "the cadence of the movement is an imperfect one." 
this whole section as a projection of the motive G\#-B that elsewhere (and more obviously) punctuates the structure? Or, should we hear the dominant triad in the upper register at the end of the first adagio, or the interval G\#-E in the upper register at the end of the second adagio, as neat encapsulations of the bass progressions that I suggest are crucial to these sections? To both questions, I would answer, reluctantly, "perhaps" - but one might be forgiven for finding either interpretation tempting. Korsyn is tempted to go even further. He suggests that a hypothetical version of the opening Vivace in which the modulation to B Major is completed without interruption (and thus the interval G\#-B composed out over the span mm. 1-9) acts as a kind of spectral presence that affects our perception of what really does happen; in other words, a might-have-been influences our listening (Korsyn 1983: 38-39, 41, 43). This is an especially abstruse suggestion, requiring the palpable presence of material that does not actually exist in the score.

But such speculation is fueled by the obvious concern for intellectual order within Opus 109. Both the sketches and the final score confirm that the interval G\#-B as the kingpin of the structure of the first movement was consciously developed by Beethoven. (Korsyn notes how the relationships involving this interval are made explicitly audible (Korsyn 1983: 44).) And it is certainly true that recondite devices - the composing out of intervals and triads, the projection of melodic ideas onto the harmonic plan, the functioning "presence" of absent roots - can be found in other music of Beethoven's last years. Nowhere does the musicological cliché "organic unity" apply more than in some of Beethoven's dense late works, which seem unified even where they do not readily yield up the exact nature of their unity.

Which did Beethoven intend us to perceive in the adagio sections: the improvisatory character that is the listener's first impression, or the structural density I tried to reveal above? I believe that both were intended - and further, that the tension this implies between surface and substructure takes us to the very essence of Opus $109 .{ }^{23}$ Combining deliberate intellectual developments (such as the projection of the interval G\#-B) with what seem to be acts of pure will (such as the interpolation of $\mathrm{C}$ Major to sweep away an intersection of compositional

23 Though, as Note 19 points out, I take issue with Dahlhaus's specific analysis of Opus 109, the chapter in which it occurs, "'Subthematicism' " (1991: 202-218), strikes me as an important contribution to our understanding of the later Beethoven. I agree with Dahlhaus that the tension between surface variety and subthematic order gives the first movement of Opus 109 its peculiar character, even if we disagree on the exact locus of order. Indeed, Dahlhaus too discusses this tension, in explicitly dialectical terms (see, for example, 1991: 202). 
problems), Opus 109 seems to be the product of an especially potent union of cerebration and instinct.

What these observations suggest is a strong strain of dualism in Opus 109 that is essential to the meaning of the work, and that is supported both by analysis and compositional genesis. Dualism is at the heart of my multi-layered analysis of the adagio sections, and is a larger implication of this analysis in light of received accounts by other scholars of the rest of the movement and sonata. More specifically, this dualism takes the form of dialectical argument, in which contrary ideas are brought together for the purpose of proposing a higher synthesis. Opus 109 is a study in dialectical tension. Drawing on the analysis above, I identify at least six distinct levels of structure on which this tension can be perceived.

First, the first and second movements as wholes act in a kind of thesis-antithesis relationship, to which the third movement's song-like theme and variations act as a resolving synthesis both motivically and tonally. ${ }^{24}$ Relevant in this respect are Schenker's, Korsyn's, and Marston's accounts of how the rising interval G\#$B$ in the first movement is definitively answered by the descending progression B-A-G\# at the end of the theme of the third movement - which, owing to the $d a$ capo device, is the last thing we hear in Opus 109..$^{25}$ This thesis-antithesis relationship is apparent in the not merely divergent but utterly opposed characters of the two movements. As in the "Hammerklavier" Sonata, the Ninth Symphony, and the String Quartet in B-flat Major, Opus 130, the second movement here is a scherzo that can be heard as a parody of the first movement. In all respects, the second movement of Opus 109 is the polar opposite of the first: its key is the tonic minor; its texture is lean, angular, contrapuntal, and continuous; its affect is taut and fierce (Mellers calls it "music of the Blakean Tyger" (Mellers 1983: 208)). In fact, its opening two bars outline the rising interval G-B in the treble, parodying the interval G\#-B that opens the first movement, and once again recalling the conflicting note pair G-G\#. (Recall the pedal marking that binds the two movements together.) The adjacency of the lush first

${ }^{24}$ Mellers posits the idea of "Song" as the goal of Opus 109: he writes (1983: p. 201) that "it is precisely the song's discovery that the sonata is 'about'." Interesting in this regard is Meredith's observation (1985a: I, 222) that while the first edition of Opus 109 (and subsequent practice) gives Gesangvoll as the main character marking for the third movement, Beethoven's Reinschrift in fact says Gesang - somewhat loftier term that perhaps substantiates Mellers's thesis.

${ }^{25}$ Marston's discussion of the "incompleteness" of the first movement (1986c: 31-36) develops an idea briefly discussed in Schenker 1913: 25, and which Marston translates in 1986c: 24. But caveat emptor; see Note 22. See also Korsyn 1983: 213. 
and feline second movements creates dialectical tension on the level of the structure of the whole sonata.

Second, the widely divergent Vivace and adagio theme groups within the first movement represent, of course, contrast in the extreme; the development introduces some hint of adagio material into the Vivace; and the coda, which absorbs the adagio material finally into the Vivace (recall $\mathrm{mm}$. 75-85), acts as a resolution of the tension between them - if only a temporary one in terms of the sonata's overall structure. I also showed how the second adagio takes up structural features of the Vivace sections. So as much as the first movement features two strongly contrasting ideas, it is also concerned to show that the two share technical features, and infiltrate each other's space, eventually to be reconciled to some degree. In fact, dialectical tension is so much the point of this movement that Beethoven accords approximately equal performance time to the two ideas, and so the designation of the adagio material as a second subject group is all but nonsensical. It is more an equal partner in a dialectical conception.

Third, within the adagios themselves, the two-part, statement-variation structure plays one half against the other, accumulating considerable tension and setting up a strong call for resolution to the dominant and tonic, respectively.

Fourth, within the second adagio, the C Major material adds a second layer of parenthesis to the structure, and so a sense of dialectical tension at the even more local level of one half of a section.

Fifth, three important note pairs - A/A\#, C/C\#, and G/G\# - punctuate the structure at several levels, affecting everything from melodic ornamentation to harmonic goals to the very key relationship of the first two movements. The conflicts of these note pairs (all directly related to the interval G\#-B) again create various levels of structural tension fully worked out only in the third movement.

Sixth and finally, dialectic may be perceived at an even more refined level, that of single events that can be heard simultaneously in two different ways. I observed that the bass F\# of $\mathrm{m} .12$ functions melodically as part of the B Major triad composed out in the lowest register. But we saw too that, on a more subliminal level, the diminished seventh chord this bass note supports functions

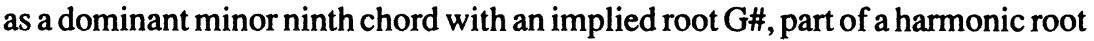
progression subtly related by inversion to the recapitulated adagio. M. 12 thus offers us a moment in which the bass is and is not the focus of attention. In the second adagio, I showed how the shifts in the bass from $G \#$ to $G$ and back again form "parentheses" around the C Major material, but also act as a clue to the devices of inversion and substitution that inform this whole section. And further, 
I suggested that while the $\mathrm{C}$ Major material is made to stand conspicuously apart from the other activity in the second adagio, it also, paradoxically, is intimately tied up with it, the root movement of the whole of mm. 61-65 inverting that of $\mathrm{mm} .12-15$. In these examples, single perceived events have several implications, serving different elements of the structure that exist on different levels and in different time scales. The result is again a tension that is not resolved until later in the movement. These are unusually subtle examples of Beethovenian dualism, involving not his usual opposition of contrasting themes or sections, but opposition of diverse perceptions of the same aural events.

Thus at every level of structure we can perceive conflicts, with resolutions at one level overtaken by the renewal of tension at some higher level. If there is something we could call "subject matter" in Opus 109, it is this dialectic - this synthesizing of contrary tensions. So deceptively slight and sonorous a work, Opus 109 in fact substitutes density for duration of structure (a "heavenly brevity", perhaps). Subjected to sudden, alienating changes and transitions, Opus 109 manifests in its final form the sense of struggle and evolution of its compositional genesis. In this sense, its history became its content.

We may also wish to see Opus 109 as a particularly good representative of some of the dualisms so potent in Beethoven's late style in general. The divergence of form and content in the first movement, for example, reflects the tension between Classicism and Romanticism in his music. In broadest outlines the first movement scans as almost a précis of sonata-allegro form; yet, the musical material within these formal divisions is unprecedented in a sonata-allegro, and has closer affinities with a Bach prelude or recitative, a C.P.E. Bach fantasy, a Romantic mood piece, or indeed, a Beethoven improvisation. Meredith has written at length of the relationship between sonata and fantasy in the first movement (Meredith 1985a: I, 256-264, and 293-295); in his words, the first movement has "one foot in both worlds"(Meredith 1985b: 716). This movement reflects too the tension between idea and sonority in so much of Beethoven's late music. The structure is worked out in incredible detail at every structural level; yet, the movement persists in being at one with its instrumental medium. One of Beethoven's tightest structures, Opus 109 contains also some of his most idiomatic, most beautiful, most Romantic piano writing.

However much we are tempted to pursue the critical implications of dialectic in Opus 109, we must be wary of lapsing into programmatic discussion. Mellers' likening of the theme groups in the first movement to Blake's Innocence and Experience is descriptively acceptable, yet perilously close to the programmatic. The implications of dialectic in Opus 109 are rather more philosophical than 
literary or pictorial, and the sonata should be assessed not in terms of any one "meaning", but in terms of its capacity for dialectical interpretation. It can be understood, for example, in terms of some of the philosophical currents of Beethoven's day - Hegel's dialectical triad, for example, or his conception of Werden as the basic condition of life. ${ }^{26}$ Schopenhauer's opposition of Will and Idea is perhaps relevant to the relationship of adagio and Vivace material in the first movement. We might pursue this track almost ad infinitum, for dualism is at the heart of much philosophy. If the universe of Opus 109 is Hegelian, it is no less Heraclitean.

No philosophical affinity we can draw is as important as that such affinities can be drawn at all. Given Beethoven's own tendency towards philosophical speculation, it is by no means absurd to posit philosophical ideas in Opus 109. Neither should it surprise us if the particular ideas are dialectical, for Beethoven himself was the most contradictory of men, an "unlicked bear" who aspired to "the starry sky above us". Ultimately, Opus 109 should be considered as an archetypal statement, as an incarnation of the principle of dialectic. It transcends mere technical, programmatic, biographical, or historical interest by embodying a permanent condition of human experience.

\section{APPENDIX: SKETCHES}

The sketch examples that follow are all drawn from the sketch miscellany Grasnick 20b (Berlin, Deutsche Staatsbibliothek), which consists of twenty-four unbound folios of various contents, dates, sizes, paper types, and watermarks. The first six folios are single desk sketchbook leaves stitched together, and of these, fols. $3 \mathrm{r}-5 \mathrm{v}$ and $6 \mathrm{v}$ contain sketches for the first movement of Opus 109. Fols. 2-6 of Grasnick 20b were originally part of the Wittgenstein sketchbook (Bonn, Beethoven-Haus, Bsk 1/49); they followed fol. 44 of the sketchbook, the present last leaf. (See the Meredith and Marston dissertations for more complete information on Grasnick 20b; see their "Origins" articles for discussions of the exact dating of these and other sketches for the first movement; and see the Appendix to Marston's "Schenker and Forte Reconsidered", pp. 36-37, for a summary of all of the sketch sources for Opus 109.)

${ }^{26}$ We might more generally see Hegel's dialectic at work in the very principle of sonata that was integral to Beethoven's compositional personality. Others have noticed an affinity between Beethoven and Hegel: see, for example, Solomon 1979: 248-266. Solomon moves beyond Hegel to set Beethoven firmly in the climate of ideas of his time. Mellers (1983: 11-29) sees Beethoven as an embodiment of Enlightenment philosophy, and Maynard Solomon (1977 and 1988) is much concerned with the composer's place in social, cultural, political, and philosophical history. 
The transcriptions that follow are my own, based on consultation of the originals in facsimile. (I am very grateful to Dr. Meredith for lending me copies of fols. $3 r-5 v$ of Grasnick 20b.) I also consulted - though often departed from - the transcriptions in the Meredith and Marston dissertations, and I have incorporated several generous suggestions from William Kinderman.

The following editorial practices should be noted. Material in square brackets or in dotted lines (barlines, ties) is editorial. Questionable transcriptions are indicated thus: [?]. An oblique stroke [/] or X indicates a deletion in Beethoven's hand. Distinctions between ink and pencil material in the originals are indicated where necessary to clarify layers of addition, deletion, or revision. Running editorial time signatures are given to clarify Beethoven's thought and/or to facilitate analogy to the final score (though Beethoven is often not scrupulous about filling bars with correct note values). Stave numbers are circled in the left margin; "a" and "b" are used to indicate continuity in a difficult passage in Sketch 5. All sketches proceed continuously from stave to stave unless otherwise indicated; in Sketch 3, material at the bottom of fol. 3r continues at the top of 3v. Dotted double bar lines indicate divisions of idea within single sketches. The marking [etc.] at the end of a sketch indicates that the sketch continues in the original, but is no longer directly relevant to my purposes in the text; at the beginning of a sketch, [etc.] indicates that related sketching precedes the relevant transcription.

(5)
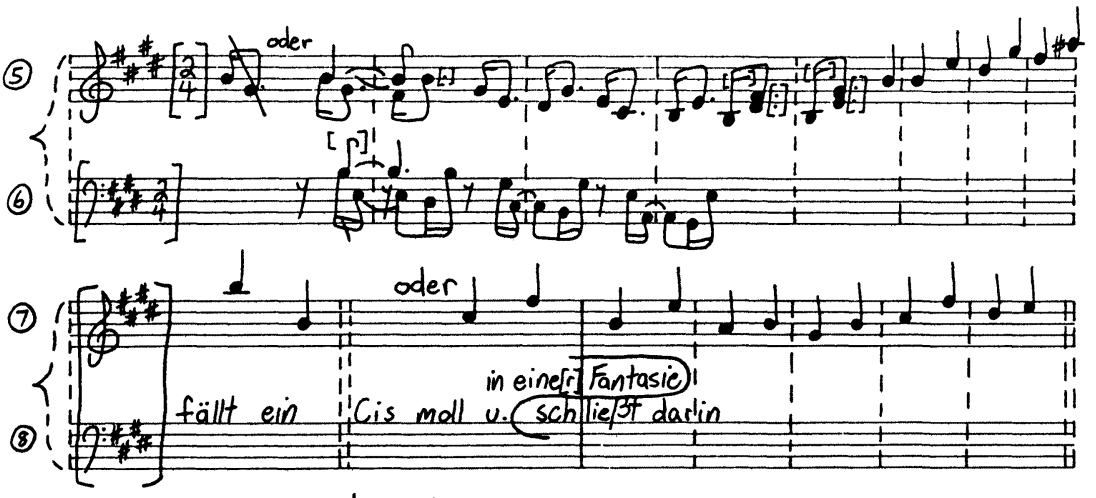

(9)

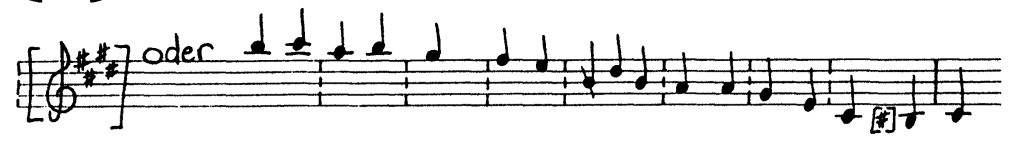

Sketch 1: fol. 3r/st. 5-9 (cf. Opus 109/I, mm. 1-8) 

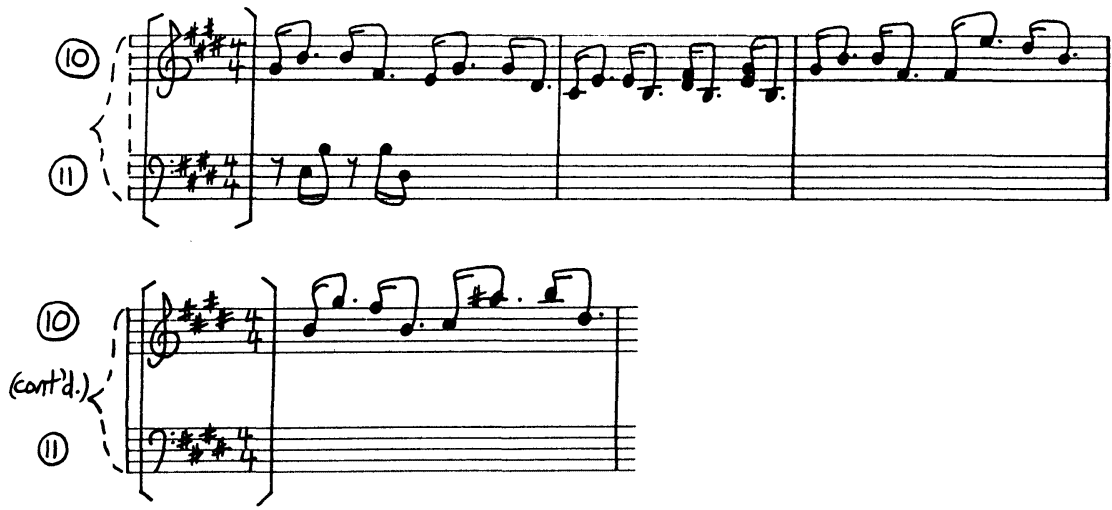

Sketch 2: fol. 3r/st. 10-11 (cf. Opus 109/I, mm. 1-8)

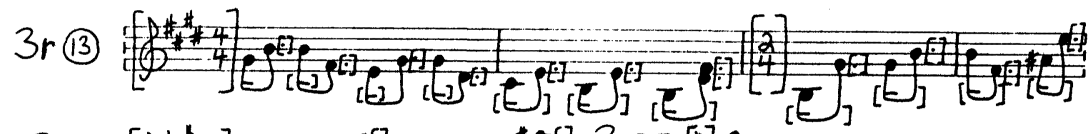

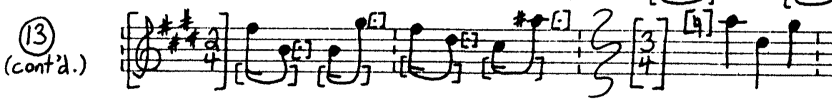

(14) 告

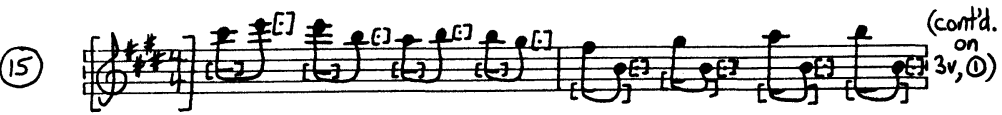

(16) [Stave 16 is blank. except for uncelated marginal comments in the

Sketch 3: fol. 3r/st. 13-16 and fol. 3v/st. 1 (cf. Opus 109/I, mm. 1 - ca. 15?) 


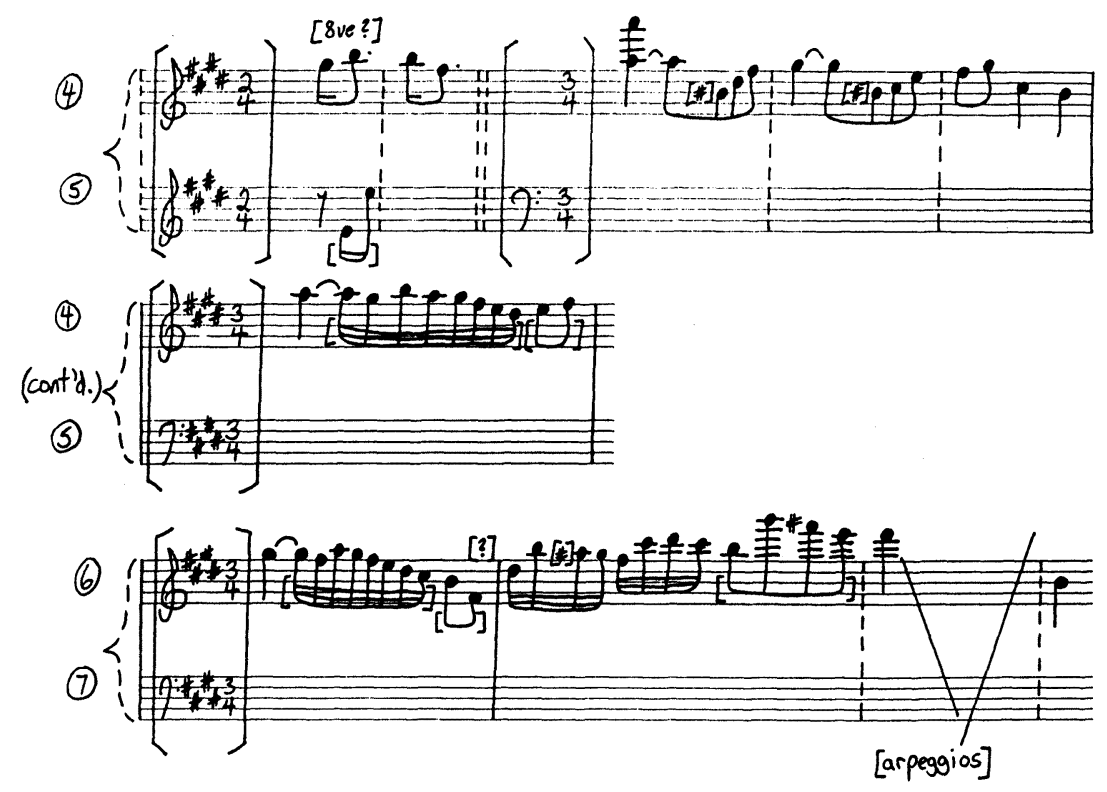

Sketch 4: fol. 3v/st. 4-7 (cf. Opus 109/I, mm. 1-15)

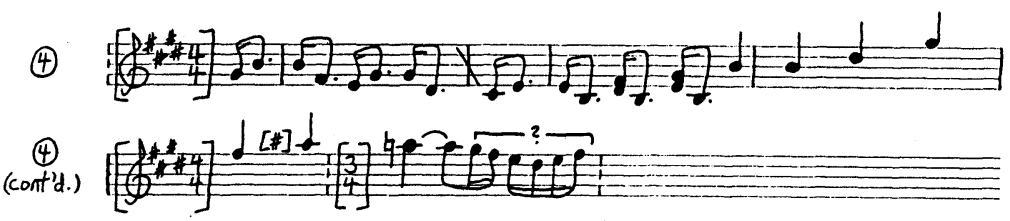

(5)a
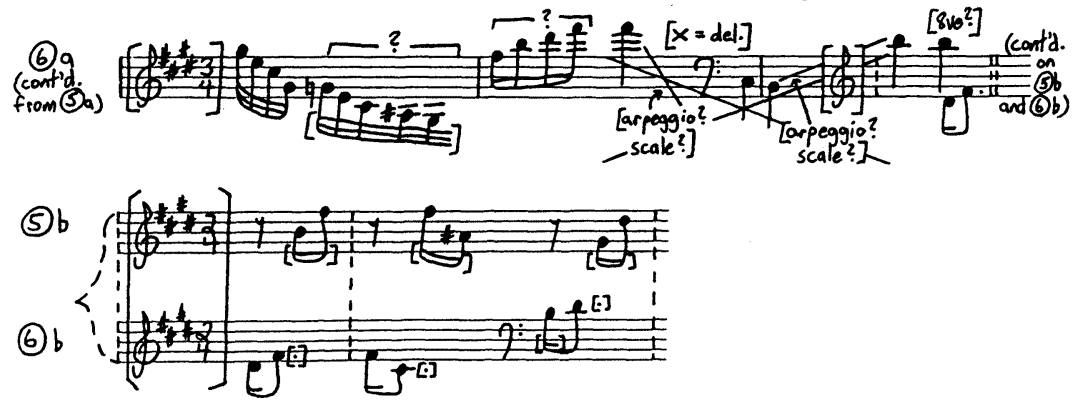

Sketch 5: fol. 4r/st. 4-6 (cf. Opus 109/, mm. 1-16) 


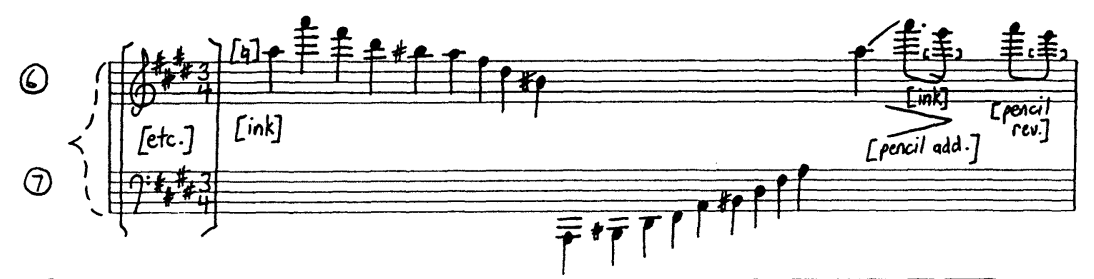

(8) [Stave 8 - is btank]
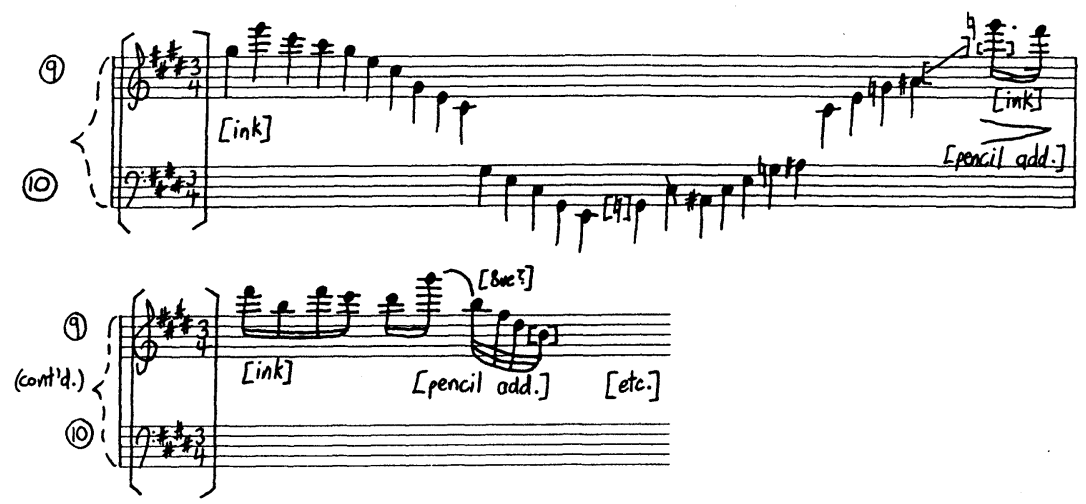

Sketch 6: fol. 4v/st. 6-10 (cf. Opus 109/I, mm. 12-14)

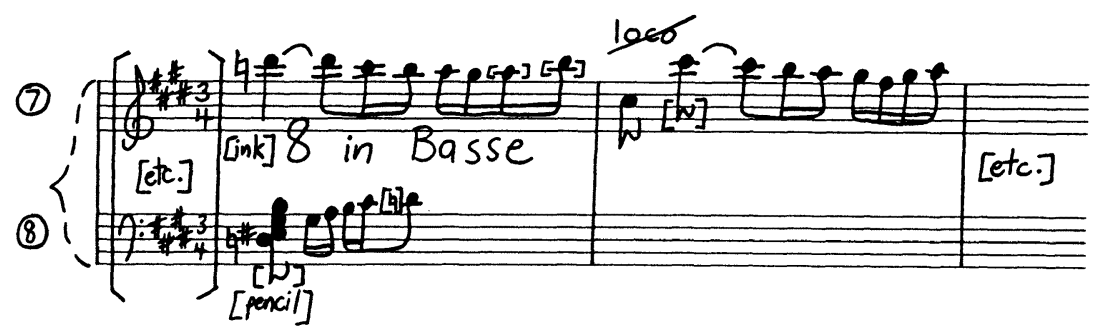

Sketch 7: fol. 5r/st. 7-8 (cf. Opus 109/I, mm. 58-59) 


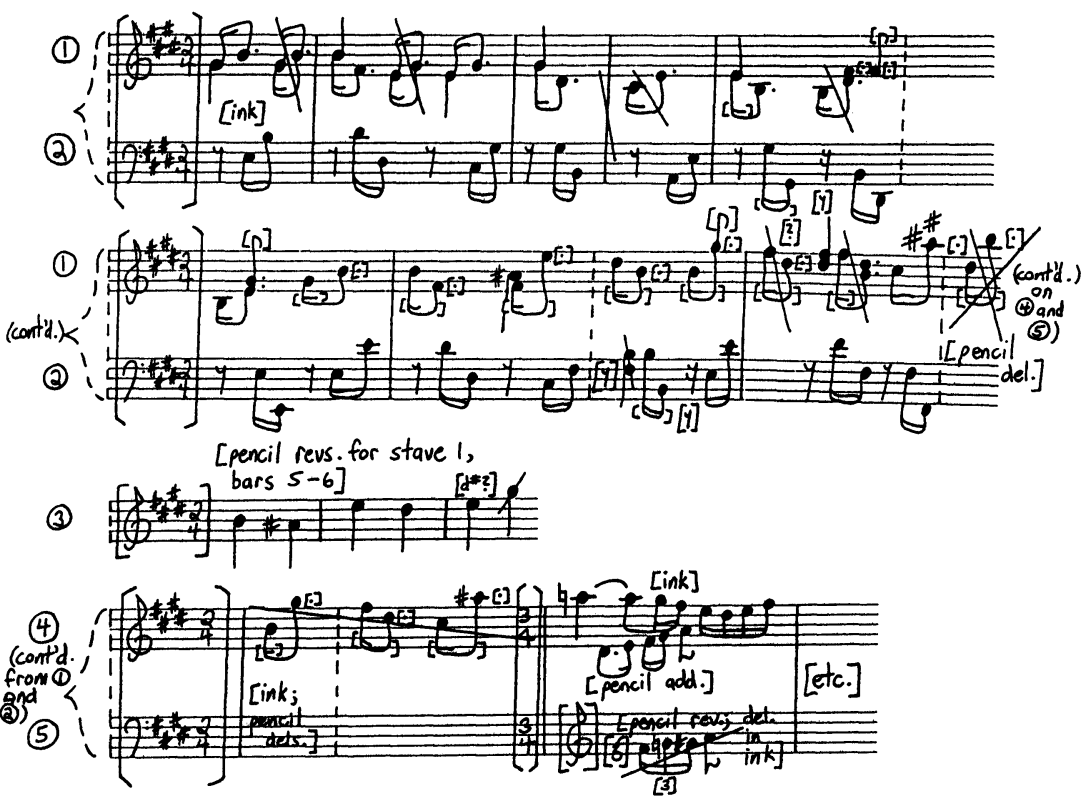

Sketch 8: fol. 4v/st. 1-5 (cf. Opus 109/I, mm. 1-9) 


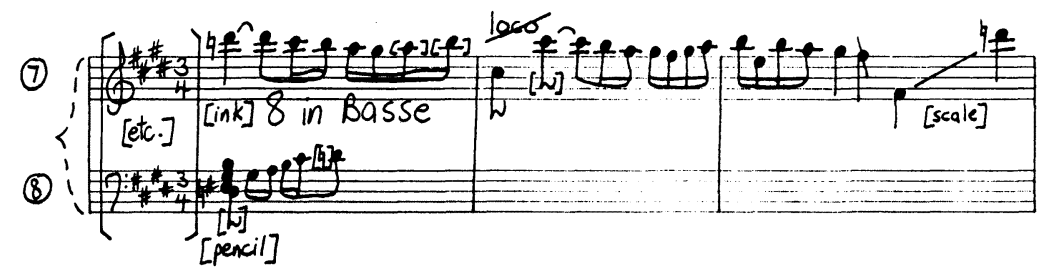

(9) $\equiv$ Istave 9 is blant.]
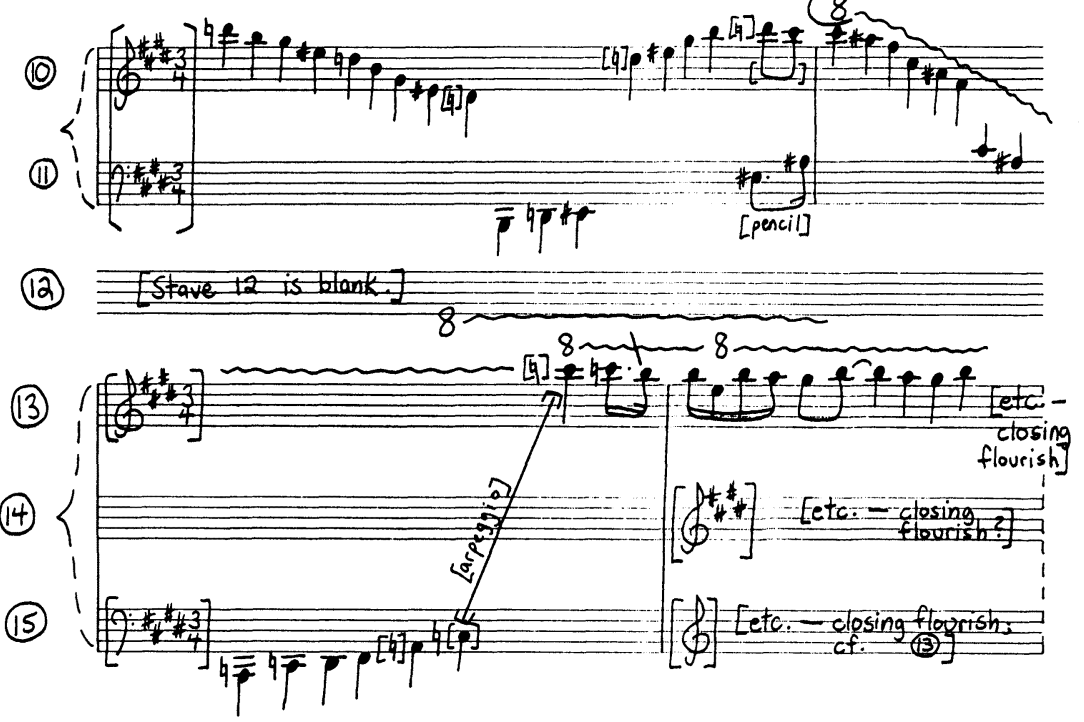

Sketch 9: fol. 5r/st. 7-15 (cf. Opus 109/I, mm. 58-63)

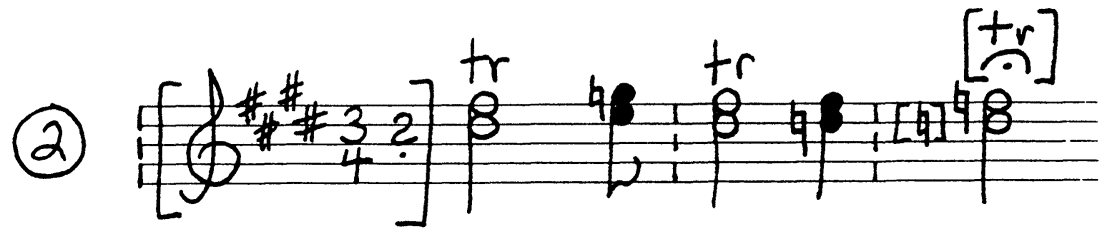

Sketch 10: fol. 3v/st. 2 


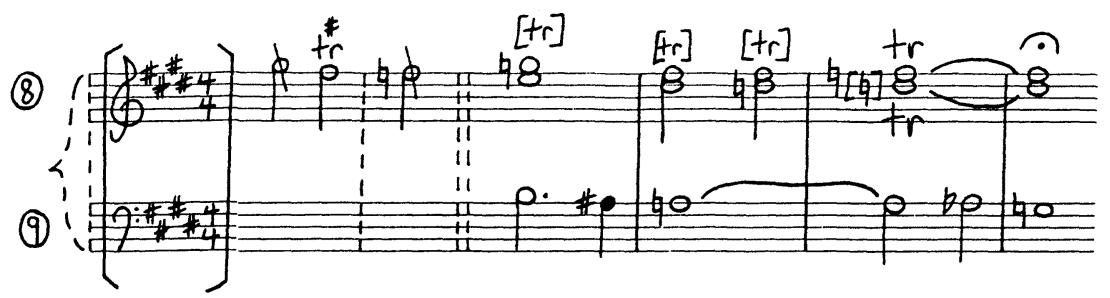

Sketch 11: fol. 3v/st. 8-9

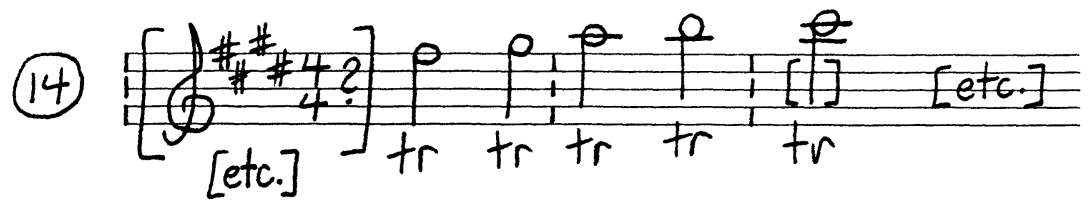

Sketch 12: fol. 3r/st. 14 (cf. Opus 109/I, mm. ca. 13-15?)

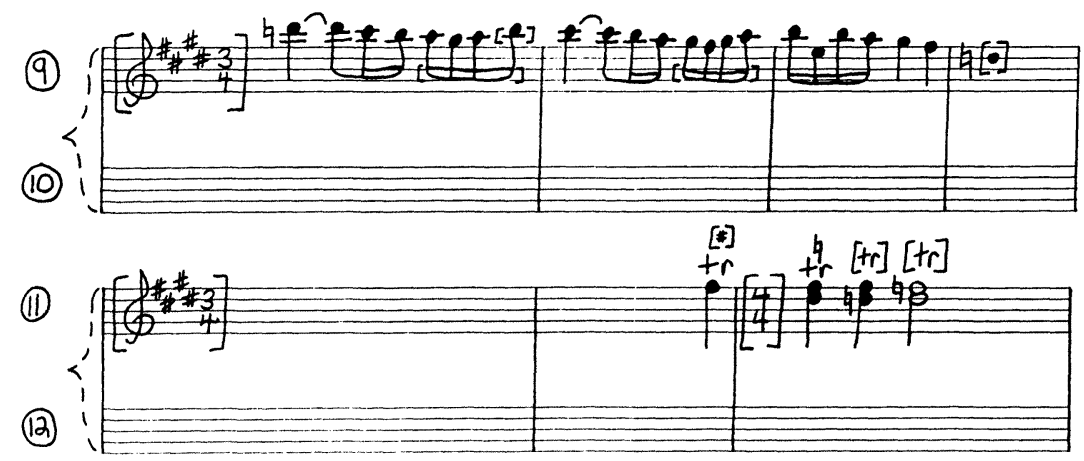

Sketch 13: fol. 4r/st. 9-12 (cf. Opus 109/I, mm. 58-64) 


\section{REFERENCES}

\section{DAHLHAUS, CARL.}

1991: Ludwig van Beethoven: Approaches to his Music. Translated by Mary Whittall. Oxford: Clarendon Press.

FORTE, ALLEN.

1961: The Compositional Matrix. Baldwin, N.Y.: Music Teachers National Association. Reprinted 1974.

\section{KINDERMAN, WILLIAM.}

1985: "Beethoven's Symbol for the Deity in the Missa solemnis and the Ninth Symphony," 19th-Century Music, 9: 102-118.

1988: "Thematic contrast and parenthetical enclosure in the piano sonatas, op. 109 and 111," in Harry Goldschmidt, ed., Zu Beethoven 3: Aufsätze und Dokumente: 43-59. Berlin: Verlag Neue Musik.

KORSYN, KEVIN.

1983: Integration in Works of Beethoven's Final Period.Ph.D. diss., Yale University.

\section{MARSTON, NICHOLAS.}

1986a: Beethoven's Sketches for the Piano Sonata in E, Opus 109. 3 vols. Ph.D. diss., University of Cambridge.

1986b: "The Origins of Beethoven's op. 109: Further thoughts," The Musical Times, 127: 199-201.

1986c: "Schenker and Forte Reconsidered: Beethoven's Sketches for the Piano Sonata in E, Op. 109," 19th-Century Music, 10: 24-42.

\section{MELLERS, WILFRID.}

1983: Beethoven and the Voice of God. London: Faber and Faber.

MEREDITH, WILLIAM.

1985a: The Sources for Beethoven's Piano Sonata in E Major, Opus 109. 2 vols. $\mathrm{Ph} . \mathrm{D}$. diss., University of North Carolina at Chapel Hill.

1985b: “The Origins of Beethoven's op. 109," The Musical Times, 126: 713-716.

\section{ROSEN, CHARLES.}

1972: The Classical Style: Haydn, Mozart, Beethoven. New York: W.W. Norton \& Company.

ROTHGEB, JOHN.

1987: Communication in "Comment \& Chronicle," 19th-Century Music, 10: 295.

\section{SCHENKER, HEINRICH.}

1913: Erläuterungsausgaben der letzten fünf Klavier-Sonaten Beethovens. No. 1: Opus 109. Vienna. Reprinted, edited by Oswald Jonas, as Beethoven: Die letzten Sonaten: Sonate E Dur Op. 109. Vienna: Universal Edition, 1971. 
1926: "Vom Organischen der Sonatenform," in Das Meisterwerk in der Musik. Yearbook 2. Munich: Drei Masken Verlag A. G. Reprinted Hildesheim and New York, 1974. ("Organic Structure in Sonata Form," translated by Orin Grossman, Journal of Music Theory, 12: 164-183. Reprinted in Maury Yeston, ed., Reading in Schenker Analysis and Other Approaches: 38-53. New Haven: Yale University Press, 1977.)

1935: Der Freie Satz. Vol. III of Neue musikalische Theorien und Phantasien. Vienna: Universal Edition. Second edition, revised and edited by Oswald Jonas, 1956. (Free Composition: Volume III of New Musical Theories and Fantasies. Translated and edited by Ernst Oster. 2 vols. Longman Music Series, edited by Gerald Warfield. New York and London: Longman, in cooperation with the American Musicological Society, 1979.)

\section{SOLOMON, MAYNARD,}

1977: Beethoven. New York: Schirmer.

1988: Beethoven Essay. Cambridge, Mass.: Harvard University Press.

SOLOMON, ROBERT C.

1979: History and Human Nature: A Philosophical Review of European Philosophy and Culture, 1750-1850. Lanham, MD: University Press of America.

TOVEY, DONALD FRANCIS.

1972: Untitled analysis of the first movement of Opus 109, in Thomas K. Scherman and Louis Biancolli, eds., The Beethoven Companion: 1,031. Garden City, N.Y.: Doubleday \& Company, Inc. 